\title{
Meiotic recombination generates rich diversity in NK cell receptor genes, alleles, and haplotypes
}

\author{
Paul J. Norman, ${ }^{1}$ Laurent Abi-Rached, ${ }^{1}$ Ketevan Gendzekhadze, ${ }^{1}$ John A. Hammond, ${ }^{1}$ \\ Achim K. Moesta, ${ }^{1}$ Deepti Sharma, ${ }^{1}$ Thorsten Graef, ${ }^{1}$ Karina L. McQueen, ${ }^{1}$ \\ Lisbeth A. Guethlein, ${ }^{1}$ Christine V.F. Carrington, ${ }^{2}$ Dasdayanee Chandanayingyong, ${ }^{3}$ \\ Yih-Hsin Chang, ${ }^{4}$ Catalina Crespi, ${ }^{5}$ Güher Saruhan-Direskeneli, ${ }^{6}$ Kamran Hameed, ${ }^{7}$ \\ Giorgi Kamkamidze, ${ }^{8}$ Kwadwo A. Koram, ${ }^{9}$ Zulay Layrisse, ${ }^{10}$ Nuria Matamoros, ${ }^{5}$ \\ Joan Milà, ${ }^{5}$ Myoung Hee Park, ${ }^{11}$ Ramasamy M. Pitchappan, ${ }^{12}$ D. Dan Ramdath, ${ }^{2}$ \\ Ming-Yuh Shiau, ${ }^{13}$ Henry A.F. Stephens, ${ }^{14}$ Siske Struik, ${ }^{15}$ Dolly Tyan, ${ }^{16}$ \\ David H. Verity, ${ }^{17}$ Robert W. Vaughan, ${ }^{18}$ Ronald W. Davis, ${ }^{19}$ Patricia A. Fraser, ${ }^{20}$ \\ Eleanor M. Riley, ${ }^{15}$ Mostafa Ronaghi, ${ }^{19}$ and Peter Parham ${ }^{1,21}$ \\ ${ }^{1-20}$ [A complete list of author affiliations appears at the end of the paper before the Acknowledgments section.]
}

\begin{abstract}
Natural killer (NK) cells contribute to the essential functions of innate immunity and reproduction. Various genes encode NK cell receptors that recognize the major histocompatibility complex (MHC) Class I molecules expressed by other cells. For primate NK cells, the killer-cell immunoglobulin-like receptors (KIR) are a variable and rapidly evolving family of MHC Class I receptors. Studied here is KIR3DLI/SI, which encodes receptors for highly polymorphic human HLA-A and -B and comprises three ancient allelic lineages that have been preserved by balancing selection throughout human evolution. While the 3DS1 lineage of activating receptors has been conserved, the two 3DL1 lineages of inhibitory receptors were diversified through inter-lineage recombination with each other and with 3DS1. Prominent targets for recombination were D0-domain polymorphisms, which modulate enhancer function, and dimorphism at position 283 in the D2 domain, which influences inhibitory function. In African populations, unequal crossing over between the 3DL1 and 3DL2 genes produced a deleted KIR haplotype in which the telomeric "half" was reduced to a single fusion gene with functional properties distinct from its 3DL1 and 3DL2 parents. Conversely, in Eurasian populations, duplication of the KIR3DL1/S1 locus by unequal crossing over has enabled individuals to carry and express alleles of all three KIR3DL1/S1 lineages. These results demonstrate how meiotic recombination combines with an ancient, preserved diversity to create new KIR phenotypes upon which natural selection acts. A consequence of such recombination is to blur the distinction between alleles and loci in the rapidly evolving human KIR gene family.
\end{abstract}

[Supplemental material is available online at www.genome.org. The sequence data from this study have been submitted to GenBank (http:/ / www.ncbi.nlm.nih.gov/Genbank/) under accession nos. EF582383, EU267269-71, F]158650-60, and F]459734.]

Among the most polymorphic and structurally diverse human loci are genes related to immune function (Redon et al. 2006; Frazer et al. 2007; Korbel et al. 2007). A principle example is the KIR locus, which displays both polymorphic and structural diversity throughout all human populations (Parham 2005; Bashirova et al. 2006). The protein products, the killer cell immunoglobulin-like receptors (KIR), recognize determinants of conserved and polymorphic major histocompatibility complex (MHC) Class I molecules (Boyington et al. 2001). Interaction of KIR on immunesystem cells with MHC Class I on other cell types allows the health of tissues to be monitored and responded to when compromised by infection or malignant transformation. In the human MHC, the HLA complex, each of the highly polymorphic Class I genes- $H L A-A, H L A-B$, and $H L A-C$ - has some alleles that encode KIR ligands. KIR are principally found on the surface of natural killer

\footnotetext{
${ }^{21}$ Corresponding author.

E-mail peropa@stanford.edu; fax (650) 723-7456.

Article is online at http://www.genome.org/cgi/doi/10.1101/gr.085738.108.
}

(NK) cells, lymphocytes that function in the early, or innate, immune response to virus infection (Lanier 2008), but they also contribute to an early stage of reproduction, when they remodel the maternal blood vessels that will supply the placenta and nourish the fetus (Moffett and Loke 2006). KIR are also expressed on some T-lymphocytes, cells that are central to the adaptive immune response to infection (Snyder et al. 2004; Moretta et al. 2006).

In humans and other primates, the KIR are encoded by a diverse and rapidly evolving gene family that exhibits considerable species specificity due to continual gene turnover (Parham 2005; Bashirova et al. 2006). In contrast, in mice, the widely used animal model in immunology, the KIR genes are few in number (two) and do not encode NK cell receptors for MHC Class I, those functions having been assumed by the independently evolved KLRA1 (also known as Ly49) receptors (Kelley et al. 2005). This lability and plasticity in genes encoding NK cell receptors likely reflects the strengths of the different and sometimes conflicting selections imposed by the needs of immune defense and placental 
reproduction, but also by the functional and genetic complexity of matching polymorphic ligands and receptors encoded by unlinked genes (Parham 2005; Moffett and Loke 2006; Lanier 2008).

The KIR locus is part of the leukocyte receptor complex (LRC) on human chromosome 19, which comprises several families of cell-surface receptors expressed by cells of the immune system (Wilson et al. 2000). The KIR genes are flanked on the centromeric side by the leukocyte immunoglobulin-like receptor (LILR) gene family and on the telomeric side by FCAR, the gene encoding the receptor for immunoglobulin A that is expressed on phagocytic cells. Human KIR haplotypes vary in gene content, having between seven and 15 genes (Uhrberg et al. 1997). Each KIR haplotype is divided into two parts by three conserved framework regions. The centromeric part contains KIR2D genes encoding HLA-C receptors, and the telomeric part contains KIR3D genes encoding HLA-A and -B receptors (Bashirova et al. 2006). The latter two genes, comprising KIR3DL1/S1 and KIR3DL2, are the subject of this study. KIR3DL1/S1 recognizes sequence motifs at residues 77-83 of HLA-A and HLA-B allotypes that form the Bw4 antigen, or epitope, defined by HLA serology (Cella et al. 1994; Gumperz et al. 1995; Thananchai et al. 2007), and KIR3DL2 recognizes HLAA3 and-A11 (Dohring et al. 1996; Pende et al. 1996).

Like HLA-A and -B, KIR3DL1/S1 is a highly polymorphic protein with more than 60 allotypes defined (Robinson et al. 2006). The natural variation affects receptor function by altering the frequency of cellular expression, abundance at the cell surface (Pando et al. 2003; Thomas et al. 2008), avidity and specificity for ligand (O'Connor et al. 2007; Thananchai et al. 2007), and the nature-either inhibitory or activating-of the intracellular signals generated upon ligand engagement (Carr et al. 2007). Furthermore, a person's combination of HLA-A, HLA-B, and KIR3DL1/S1 allotypes influences the development and function of the NK cell repertoire (Foley et al. 2008; Yawata et al. 2008), and in the population, such combinations are associated with disease susceptibility and progression, notably for HIV infection (Martin et al. 2007). The foundation for $3 D L 1 / S 1$ variety is three ancient lineages of alleles-3DS1 lineage encoding activating receptors and 3DL1-005 and 015 lineages encoding inhibitory receptorsmaintained by balancing selection for $>3$ million years and present in all modern human populations (Norman et al. 2007). Of the three lineages, $3 D S 1$ is essentially homogeneous, whereas both $3 D L 1$ lineages have been extensively diversified by point mutation and recombination. Because recombination with other KIR genes and between KIR3DL1/S1 lineages has the potential to erode the lineage distinctions, we examined the impact that meiotic recombination has had on the KIR3DL1/S1 locus and on human NK cell functional diversity.

\section{Results}

\section{Generation of KIR3DL1/S1 diversity by intergenic recombination}

In humans, the hominoid KIR lineage II is represented by two genes: 3DL1/S1 encoding NK cell receptors for the Bw4 epitopes of HLA-A and HLA-B; and 3DL2 encoding NK-cell receptors specific for HLA-A*03 and HLA-A*11 (Rajalingam et al. 2004). Not fitting with this picture is the $3 D L 1 / 2 v$ cDNA, which encodes extracellular domains like 3DL1 and intracellular domains like 3DL2 (Shilling et al. 2002). To distinguish if the $3 D L 1 / 2 v$ cDNA arises from transcription of a single gene or the splicing together of transcripts from both $3 D L 1$ and $3 D L 2$, we analyzed genomic DNA from three healthy donors having different $3 D L 1 / 2 v$ variants and one $3 D L 1 / 2 v$ donor who lacked $3 D L 1 / S 1$ because of deletion of this locus from the other KIR haplotype (Norman et al. 2004). The results unequivocally demonstrated that $3 D L 1 / 2 v$ represents a unique hybrid gene for which exons $1-5$ and associated introns are like $3 D L 1$, and exons $6-9$ and associated introns are like $3 D L 2$ (Fig. 1A, upper haplotype). In all four donors, the $3 D L 1 / 2 v$ gene was shown to be flanked by $2 D L 4$ on the upstream (centromeric) side and by FCAR on the downstream (telomeric) side. This gene organization is unusual, differing from the more common situation (Wilson et al. 2000) where $3 D L 1$ is downstream from $2 D L 4$, $3 D L 2$ is upstream of FCAR, and $2 D S 4$ lies between $3 D L 1$ and $3 D L 2$ (Fig. 1A, lower haplotype). These results raised the possibility that $3 D L 1 / 2 v$ arose through a non-homologous recombination between $3 D L 1$ and $3 D L 2$ that deleted the $3^{\prime}$ part of $3 D L 1$, the entire $2 D S 4$ gene, and the $5^{\prime}$ part of $3 D L 2$. If true, then individuals carrying $3 D L 1 / 2 v$ should never be heterozygous for exons $1-5$ of $3 D L 2$ or exons $6-9$ of $3 D L 1 / S 1$. Population analysis was performed to test this hypothesis.

$K I R 3 D L 1 / 2 v$ is restricted to sub-Saharan Africans and related populations such as African-Americans and Afro-Caribbeans, in which it is present at frequencies of up to $6.5 \%$ (Norman et al. 2007). Panels of $653 D L 1 / 2 v^{+}$and $653 D L 1 / 2 v^{-}$Africans were genotyped for heterozygosity in the sequences encoding the extracellular and intracellular domains of $3 D L 1$ and $3 D L 2$, and also for $2 D L 4$ as a control. Whereas the $3 D L 1 / 2 v^{-}$Africans exhibited significant heterozygosity in both the $3^{\prime}$ and $5^{\prime}$ parts of the $3 D L 1$ and $3 D L 2$ genes, the $3 D L 1 / 2 v^{+}$Africans lacked heterozygosity in the 3 '-exons of $3 D L 1 / S 1$ and the 5 '-exons of $3 D L 2$ (Fig. 1B). These results, showing that $3 D L 1 / 2 v$ is not on the same haplotypes as $3 D L 1$ or $3 D L 2$, are consistent with $3 D L 1 / 2 v$ having been formed by a recombination-mediated deletion that fused exons 1-5 of $3 D L 1$ with exons $6-9$ of $3 D L 2$. As a consequence, $3 D L 1 / 2 v$ has an allelic relationship with both $3 D L 1$ and 3DL2 (Supplemental Fig. S1). Because $3 D L 1 / 2 v$ is overall more structurally similar to $3 D L 1$ than $3 D L 2$, the three $3 D L 1 / 2 v$ variants were assigned names in the $3 D L 1 / S 1$ series: $3 D L 1^{*} 059,3 D L 1^{\star} 060$, and $3 D L 1^{\star} 061$ (Robinson et al. 2006). The encoded allotypes, which differ by one or two amino acid substitutions, have extracellular domains that are part of the 3DL1-005 lineage, as opposed to the 3DL1-015 lineage (Fig. 1C). That $3 D L 1{ }^{*} 059$ is geographically most widespread, being present in all six African populations studied, compared to only one and two populations for $3 D L 1{ }^{*} 060$ and $3 D L 1{ }^{*} 061$, respectively (Fig. 1D), suggests that $3 D L 1{ }^{*} 059$ was the progenitor $3 D L 1 /$ $2 v$ from which $3 D L 1{ }^{*} 060$ and $3 D L 1{ }^{*} 061$ were independently derived by single point substitutions. Further supporting this evolutionary model, the $3 D L 1{ }^{*} 059$ sequence corresponds to a fusion of sequences from common $3 D L 1$ (e.g., *00501) and 3DL2 (e.g., ${ }^{*} 001$ ) alleles, whereas $3 D L 1{ }^{*} 060$ and $3 D L 1{ }^{*} 061$ are each distinguished by a unique and different substitution. From the genomic sequences, the recombination that fused parts of the $3 D L 1$ and $3 D L 2$ genes to form $3 D L 1 / 2 v$ can be located to a $30-\mathrm{bp}$ sequence within intron 5 that is located $356 \mathrm{bp}$ upstream of exon 6 , and 2780 bp downstream from exon 5 encoding the D2 domain (Fig. 1E; Supplemental Fig. S2).

The genomic location of $3 D L 1 / 2 v$ between $2 D L 4$ and FCAR is the same as that observed for Pt-KIR3DL1/2, the single chimpanzee lineage II KIR gene (Rajalingam et al. 2004; Sambrook et al. 2005), which has structural and functional properties in common with both human 3DL1 and 3DL2 (Khakoo et al. 2000). Although these similarities raised the possibility that $3 D L 1 / 2 v$ and Pt-KIR3DL1/2 share a common origin that predated the human-chimpanzee 


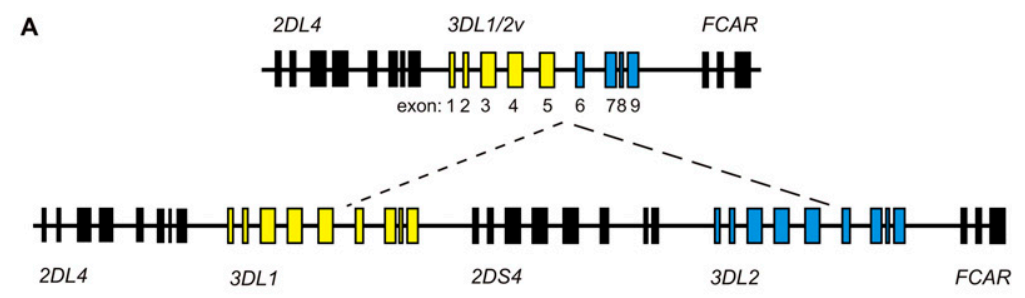

B

\begin{tabular}{|c|c|c|c|c|c|}
\hline \multicolumn{6}{|c|}{ Genotype examples } \\
\hline \multirow{3}{*}{$3 D L 1 / 2 v^{+}$} & $2 D L 4$ & $3 D L 1 / S 1$ & $3 D L 1 / 2 v$ & $3 D L 2$ & $F C A R$ \\
\hline & ${ }^{*} 006$ & ${ }^{*} 033$ & - & ${ }^{*} 008$ & $a$ \\
\hline & *00801 & - & *059 & - & $b$ \\
\hline \multirow{2}{*}{$3 D L 1 / 2 v$} & "006 & ${ }^{*} 033$ & - & ${ }^{*} 008$ & $a$ \\
\hline & ${ }^{*} 00102$ & ${ }^{*} 01501$ & - & ${ }^{*} 013$ & $b$ \\
\hline
\end{tabular}

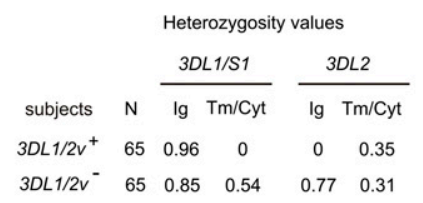

C
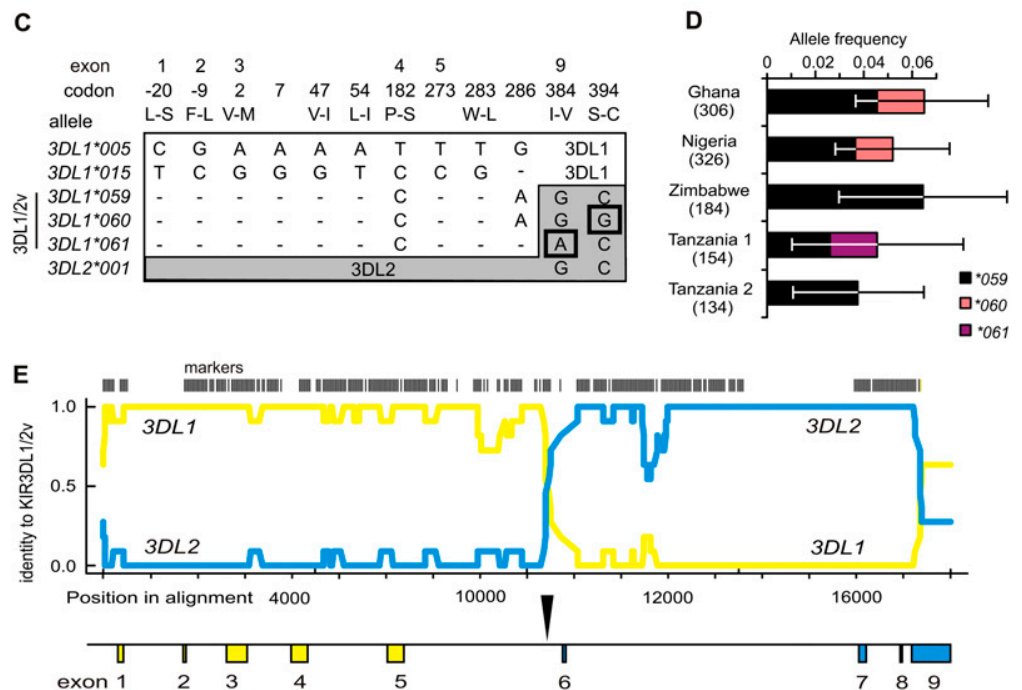

Figure 1. The $3 D L 1 / 2 v$ fusion gene is allelic to $3 D L 1 / S 1$ and $3 D L 2$. ( $A$, top) Schematic of the four $3 D L 1 / 2 v$ haplotypes that were sequenced here (Supplemental Fig. S2). (Bottom) A KIR A haplotype; (dashed lines) the genomic segment absent from 3DL1/2v haplotypes; (yellow) 3DL1; (blue) $3 D L 2$. Exons 1-5 encode the leader peptide and Ig domains (Ig), exon 6 the stalk, and exons 7-9 the transmembrane and cytoplasmic domains (Tm/Cyt). ( $B$, left) Representative genotypes from the group of 65 subjects who carry $3 D L 1 / 2 v\left(3 D L 1 / 2 v^{+}\right)$and the group of 65 who do not $\left(3 D L 1 / 2 v^{-}\right)$. (Right) Comparisons of heterozygosity observed in the $3 D L 1 / 2 v^{+}$and $3 D L 1 / 2 v^{-}$groups from segments of $3 D L 1$ and $3 D L 2$. All of the $3 D L 1 / 2 v^{+}$subjects are hemizygous for exons $6-9$ of $3 D L 1 / S 1$ and exons $1-5$ of $3 D L 2$, which corresponds to the portion absent from the KIR A haplotype. This shows the $3 D L 1 / 2 v^{+}$ subjects have $3 D L 1$ and $3 D L 2$ on one haplotype and $3 D L 1 / 2 v$ on the other. (C) Shown are the nucleotide differences in exons $1-5$ that distinguish $3 D L 1 / 2 v(3 D L 1 * 059,3 D L 1 * 060$, and $3 D L 1 * 061)$ from (white) $3 D L 1$ and in exons 7-9 that distinguish $3 D L 1 / 2 v$ from (gray) $3 D L 2$. The many nucleotide differences $(N=102)$ that distinguish 3DL1 and 3DL2 are not shown. Shown are $3 D L 1 * 00501$ and $3 D L 1 * 01502$, which represent the 005 and 015 lineages of inhibitory receptors; exons 1-5 of $3 D L 1 / 2 \mathrm{~V}$ are related to $3 D L 1 * 00501$. In exons $7-9,3 D L 1 * 059$ is identical to $3 D L 2 * 001 ; 3 D L 1 * 060$ and $3 D L 1 * 061$ being distinguished by the SNPs boxed. Codons are numbered according to the mature protein, and amino acid changes are indicated by single letter code. $(D)$ Shown are the frequencies of three $3 D L 1 / 2 \mathrm{v}$ alleles $(3 D L 1 * 059-61)$ in the five sub-Saharan African populations where they were detected. The number of haplotypes examined from each population is shown in parentheses; error bars show the $95 \%$ confidence interval of the allele frequency measurements. ( $E$ ) Shown is a pairwise identity plot from alignment of genomic sequences. (Yellow line) Signifies identity of $3 D L 1 / 2 v$ with $3 D L 1$; (blue line) the identity of $3 D L 1 / 2 v$ with $3 D L 2$; (vertical bars) the SNP markers used in this analysis. (Shown below by the vertical arrow) The crossover occurred in intron 5 during the interval from 386 to 356 bp upstream from exon 6 . A continuous sequence trace that spans the crossover is shown in Supplemental Figure S2.

separation, several lines of evidence point to $3 D L 1 / 2 v$ having evolved independently by recombination during human evolution, subsequent to the split from chimpanzees. First, the inclusion of exons $1-5$ of $3 D L 1 / 2 v$ in the 005 lineage of $3 D L 1 / S 1$ alleles (Fig. 1C), and not in either the 015 or 3DS1 lineages, indicates that $3 D L 1 / 2$ was formed after lineage divergence, which occurred subsequent to the humanchimpanzee separation (Norman et al. 2007). Thus in phylogenetic analysis, human $3 D L 1 / 2 v$ was never an out-group to $3 D L 1$ when compared with PtKIR3DL1/2 and other hominoid KIR lineage II genes (Supplemental Fig. S3A). Second, the $3 D L 1 / 2 v$ Ig-domain is estimated to have arisen $\sim 0.74$ million years ago (Mya) (95\% CI: $0.27-1.55$ Mya) (Supplemental Fig. S3B), after the three allelic lineages of $3 D L 1 / S 1$ split. As the Igdomain divergence preceded the genomic deletion event, $3 D L 1 / 2 v$ arose at a time potentially close to the emergence of modern humans ( 200,000 yr ago) (Relethford 2008). Lastly, our finding that all three variants of $3 D L 1 / 2 v$ $\left(3 D L 1{ }^{*} 059,3 D L 11^{\star} 060,3 D L 1{ }^{\star} 061\right)$ were flanked by identical sequences and $2 D L 4$ $\left({ }^{\star} 00801\right)$ and $F C A R\left({ }^{*} 001\right)$ alleles, despite genome-wide lack of LD in sub-Saharan Africans (Campbell and Tishkoff 2008), points to a recent origin for $3 D L 1 / 2 v$.

In conclusion, the results are all consistent with $3 D L 1 / 2 v$ having been formed during a meiotic recombination in a human ancestor that deleted DNA from the telomeric region of a KIR haplotype to fuse the 5' part of a 3DL1 allele with the 3' part of a 3DL2 allele. Although the size of the deletion is uncertain because of gene-content variability, the most likely event would have involved the $A$ haplotype configuration shown in Figure $1 \mathrm{~A}$ with deletion of $\sim 30 \mathrm{~kb}$ containing all of $2 D S 4$ and parts of $3 D L 1$ and 3DS1. That the telomeric part of most chimpanzee KIR haplotypes has similarly, but independently, evolved to resemble that of the KIR3DL1/2v-containing haplotypes, points to this simplified structure having conferred advantage in at least two different circumstances.

\section{Generation of KIR3DL1/S1 diversity by interlineage recombination}

Domain-by-domain phylogenetic analysis of $613 D L 1 / S 1$ alleles shows that a minimum of $12(\sim 20 \%)$ alleles arose through intragenic meiotic recombination (Fig. 2). Most of these events (nine) involved recombination between two of the three different 3DL1/S1 lineages: 3DL1-005, 3DL1-015, and 3DS1. The two regions of the molecule most affected by recombination are the D0 domain (five events) and position 283 (three events) near the C-terminal end of the D2 domain (Fig. 2A). Both these regions bear a strong signature of positive selection in human populations (Norman et al. 2007) and have distinct functions that affect the strength and specificity of the KIR3DL1/S1 interaction with MHC 
Class I. The D1 and D2 domains form the ligand-binding site, and the D0 domain is an enhancer that modulates the strength of the ligand-receptor interaction (Khakoo et al. 2002).

Three 3DL1/S1 allotypes likely arose by meiotic gene conversion. Genomic sequence comparison indicates that $3 D L 1{ }^{*} 009$ was formed by conversion between $3 D L 1{ }^{*} 001$ and $3 D S 1{ }^{*} 01301$ that involved a sequence of 1.4-1.5 kb containing exons 2 and 3 (Fig. 2C; Supplemental Fig. S4). Consequently, 3DL1*009 combines the D0 domain from $3 \mathrm{DS} 1^{*} 013$ with the other domains from $3 \mathrm{DL} 1{ }^{*} 001$. In analogous fashion, 3DL1*054 combines the D1 domain from $3 \mathrm{DS} 1{ }^{*} 013$ with the other domains from $3 \mathrm{DL} 1{ }^{*} 002$ (Thomas et al. 2008). The third candidate for gene conversion involves the arginine/histidine dimorphism at position 31 in the D0 domain. Uniquely, this dimorphism has been introduced into all three 3DL1/ S1 lineages, through conversions involving a maximum of 70-110 bp of DNA (Fig. 2D). Residue 31 is part of a positively selected cluster of surface residues implicated in the enhancing function of the D0 domain (Khakoo et al. 2002). In contrast to these three products of interlineage gene conversion, $3 \mathrm{DL} 1{ }^{\star} 042$ combines the leader peptide and D0 domain from $3 \mathrm{DS} 1{ }^{*} 013$ with the other domains from $3 \mathrm{DL} 1^{*} 005$ and was likely the product of a simple crossover between the two alleles (Fig. 2B). Similarly, 3DL1*001 and 3DL1*043 combine a D0 domain derived from the 3DL1-005 lineage with the other domains from the 015 lineage. Although the three lineages and their distinctive differences have been maintained by balancing selection

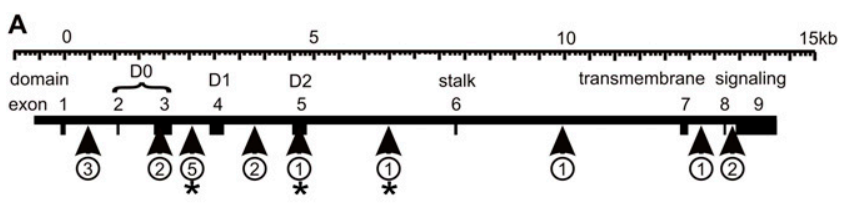

B
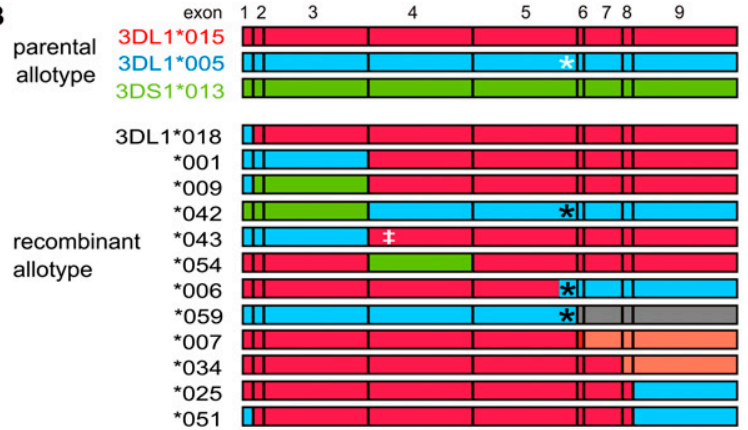

C

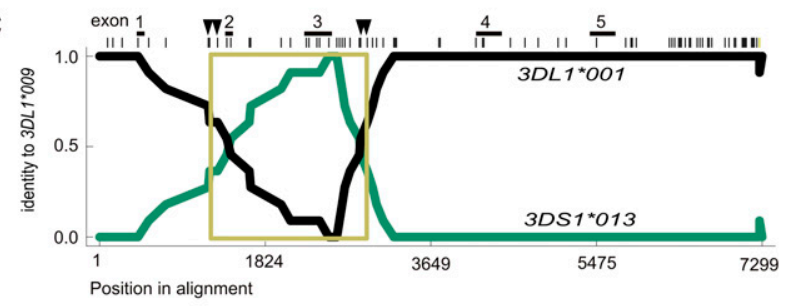

D Do
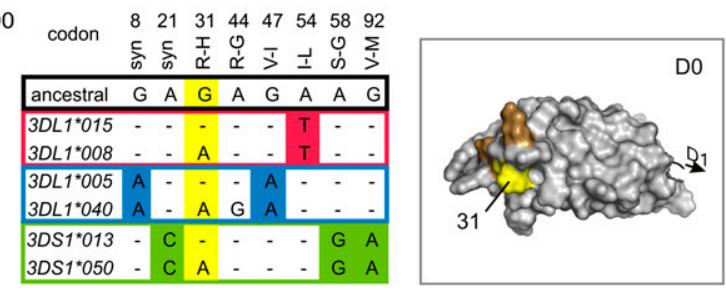

over several million years, we also see that these features have regularly been recombined to produce 3DL1/S1 allotypes with distinctive functions that presumably confer some selective advantage in the short term.

\section{KIR3DL1/2v is an inhibitory receptor with distinctive specificity for Bw4 epitopes of HLA-A and -B}

A characteristic of $3 D L 1 / S 1$ gene expression is that each allele is expressed only by a fraction of NK cells, and the fraction varies with the allele (Gardiner et al. 2001; Chan et al. 2003; Trundley et al. 2007; Thomas et al. 2008). We therefore assessed cell surface expression of 3DL1/2v. The KIR3DL1-specific antibody, DX9, bound to a subset (17\%) of peripheral blood NK cells from a donor heterozygous for $3 D L 1{ }^{*} 059$ and $3 D L 1{ }^{*} 004$. Because $3 D L 1{ }^{*} 004$ is not expressed at the cell surface (Pando et al. 2003), this DX9 binding had to be due to the expression of $3 \mathrm{DL} 1{ }^{*} 059$ (Fig. 3A). Comparison of peripheral blood NK cells from different donors, and expressing different 3DL1 allotypes, showed that the level of DX9 binding to 3DL1*059 was intermediate between that observed for $3 \mathrm{DL} 1{ }^{*} 001$ and $3 \mathrm{DL} 1{ }^{*} 005$ (Fig. $3 \mathrm{~A})$. This binding hierarchy correlates with the two dimorphisms that distinguish the extracellular domains of the three allotypes. Highbinding $3 \mathrm{DL} 1{ }^{*} 001$ has proline 182 and tryptophan 283 , whereas low-binding $3 \mathrm{DL} 1{ }^{*} 005$ has serine 182 and leucine 283 ; 3DL1*059 is a hybrid of the two that combines proline 182 with leucine 283.

We next assessed the capacity of $3 \mathrm{DL} 1 / 2 \mathrm{v}$ to function as an inhibitory receptor. To do this, we used an in vitro assay in which the NKL cell line kills the HLA Class I-deficient 221 cell line. This killing can be inhibited if the NKL cells are transduced with an inhibitory KIR and the 221 target cells are transfected with a complementary HLA Class I ligand (Gumperz et al. 1995). Transduction of the NKL cell line with $3 D L 1^{*} 059$ cDNA gave an NK cell for which $3 \mathrm{DL} 1{ }^{*} 059(3 \mathrm{DL} 1 / 2 \mathrm{v})$ is the only KIR expressed at

Figure 2. Motif and domain shuffling between three lineages diversifies $3 D L 1 / S 1$. (A) Shown to scale is the genomic organization of the $3 D L 1 / S 1$ locus. (Boxes) Exons; exons 2-5 encode the three Ig domains, D0, D1, and D2. (Vertical arrows) The genomic regions and the number of recombination events detected from comparison of $3 D L 1 / S 1$ alleles. ${ }^{*}$ ) Recombination event that placed residue leucine 283 onto a different background allotype. (B) Schematic of 12 recombinant alleles of $3 D L 1 / S 1$ that were identified using domain-by-domain phylogenetic analysis. The recombinant allotypes are represented by segments colored according to allelic lineage: (red) 015, (blue) 005, (green) 3DS1. The allotypes shown at the top of the panel are encoded by the most common modern alleles: $3 D L 1 * 01502,3 D L 1 * 00501$, and $3 D S 1 * 01301$. For example, $3 D L 1{ }^{*} 001$ is identical to $3 D L 1^{*} 00501$ in exons $1-3$ and $3 D L 1{ }^{*} 01501$ in exons 4-9. (Gray) Recombination from another locus (3DL2); (pink) within-lineage recombinants. (White asterisk) Tryptophan-leucine substitution at residue 283; (black asterisk) recombination has replaced tryptophan at residue 283 with leucine; $(\ddagger)$ threonine 118 that distinguishes $3 D L 1 * 043$ from $3 \mathrm{DL} 1{ }^{*} 001$ and is shared with $3 \mathrm{DL} 1{ }^{*} 038$. (C) The pairwise identity plot shows that $3 D L 1^{*} 009$ formed by gene conversion. (Black line) Identity of $3 D L 1{ }^{*} 009$ with $3 D L 1 * 001$; (green line) identity of $3 D L 1{ }^{*} 009$ with $3 D S 1 * 01301$. The recombination included exons 2 and 3 , which encode D0. (Across the top, vertical bars) SNP markers; (vertical arrows) the minimum and maximum limits of the gene conversion. Genomic sequences used for the RDP analysis include representatives of the three allelic lineages of $3 D L 1 / S 1$ (listed in Methods). The $3 D L 1 * 009$ CDNA sequence that was independently obtained (Middleton et al. 2007) corresponds precisely to the reading frame of the locus characterized here. (D) Shown for each of the $3 D L 1 / S 1$ lineages is a pair of alleles that are dimorphic at (yellow) codon 31. Nucleotide differences in D0 are shown, and those that distinguish the three lineages are colored as in panel $A$. (Top) Amino acid substitutions with the ancestral residue first and the ancestral nucleotide immediately below. (Right panel) A homology model of D0; residue 31 (yellow) occurs in a patch of positively selected residues (orange) that were identified in Norman et al. (2007).

\section{Genome Research}

www.genome.org 
the cell surface. The specificity and function of $3 D L 1 * 059$ were examined in cytotoxicity assays and compared to the 3DL1 and 3DL2 "parental" receptors. NKL cells expressing $3 D L 1{ }^{*} 059$, $3 D L 1{ }^{*} 001$, or $3 D L 1{ }^{*} 01502$ killed HLA Class I-deficient 221 cells as effectively as untransfected NKL cells. When transfected 221 cells expressing Bw $4^{+}$HLA-B ${ }^{*} 1513$ were used as the target, reduced lysis was observed for NKL cells expressing $3 \mathrm{DL} 1 * 059$, 3DL1*001, or $3 \mathrm{DL} 1{ }^{*} 015$, compared to lysis by NKL cells that express no KIR or KIR3DL2 that has no affinity for HLA-B*1513 (Fig. 3B, left). These inhibitory effects were abrogated by the inclusion of either anti3DL1 (DX9) (Fig. 3B) or anti-HLA Class I (DX17) (data not shown) monoclonal antibodies, showing that the inhibition observed for the 3DL1-transduced NKL cells was dependent on the combination of 3DL1 on the NK cell and HLA-B* 1513 on the target cell.

The inhibition mediated by the interaction of $B^{\star} 1513$ with $3 \mathrm{DL} 1 * 059$ was comparable to that observed for $3 \mathrm{DL} 1{ }^{*} 001$ and greater than that seen for $3 \mathrm{DL} 1^{*} 015$. Thus, the Bw4 epitope of HLA-B is demonstrated to serve as a ligand for $3 D L 1{ }^{*} 059$. Similar experiments showed that interaction of $3 \mathrm{DL} 1{ }^{*} 059$ with the Bw $4^{+}$ HLA-A*3201 allotype also inhibited the lysis of transfected 221 cells, to an extent comparable to $3 \mathrm{DL} 1^{*} 015$, but less than 3DL1*001 (Fig. 3B, center). In contrast, the Bw $4^{-}$HLA-A*1102 allotype did not engage 3DL1, but interacted with $3 D L 2 * 001$ to inhibit the lysis of 221 cells (Fig. 3B, right), in a manner consistent with its HLA-A3, HLA-A11 specificity (Dohring et al. 1996; Pende et al. 1996; Hansasuta et al. 2004).

In summary, these results demonstrate that $3 \mathrm{DL} 1{ }^{*} 059$ is a functional, inhibitory cell-surface receptor with a specificity for $\mathrm{Bw} 4^{+}$HLA Class I that is characteristic of KIR3DL1. The unusual 3DL2-like signaling domain of $3 D L 1 * 059$ (Fig. 4) generates inhibitory signals that are within the range of those obtained from conventional 3DL1 signaling domains, but, as expected, does not skew the specificity of $3 D L 1^{*} 059$ toward the HLA-A* 1102 recognized by KIR3DL2. Distinguishing 3DL1*059 from the other 3DL1 allotypes examined here is the similar strength of the inhibition resulting from interactions with Bw4 epitopes on HLA-A and HLA-B "backgrounds" (Fig. 3B).

\section{KIR3DL1/2v generates weaker inhibition than KIR3DL1}

To examine further the effect of the 3DL2-like transmembrane region and cytoplasmic tail of $3 \mathrm{DL} 1^{\star} 059$, we made a mutant (m1) in which they were replaced by the homologous domains of $3 \mathrm{DL} 1{ }^{*} 001$. Reciprocally, a second mutant $(\mathrm{m} 2)$ paired the extracellular domains of $3 \mathrm{DL} 1{ }^{*} 001$ with the transmembrane region and cytoplasmic tail of 3DL1*059 (Fig. 3C, left). NKL transductants expressing these two mutants and their natural allotypes were compared in cytotoxicity assays against 221 target cells and 221 transfectants expressing $A^{*} 3201$ or $B^{\star} 1513$. This analysis showed that the combination of $3 \mathrm{DL} 1{ }^{*} 059$ and $\mathrm{B}^{\star} 1513$ gave a weaker inhibition than the combination of $\mathrm{m} 1$ and $\mathrm{B}^{\star} 1513$ (Fig. 3C, center). A similar trend was seen when the ligand was $A^{*} 3201$, but the difference was much smaller (Fig. 3C, right). For the reciprocal pair, $3 D L 1{ }^{*} 001$ gave a stronger inhibition than $\mathrm{m} 2$, a difference that was greater with $A^{*} 3201$ as the ligand than with $B^{\star} 1513$. These results show that in all combinations, the trend is to weaker inhibition when the transmembrane region and cytoplasmic domain are derived from 3DL2. Thus another potential selective advantage of $3 D L 1 / 2 \mathrm{v}$ is its capacity to generate a weaker inhibitory signal than its progenitor 3DL1 allotype.

Because 3DL1*059 and $\mathrm{m} 2$ only differ at position 283 , as do $3 \mathrm{DL} 1{ }^{*} 001$ and $\mathrm{m} 1$, this mutational analysis also showed how the
A

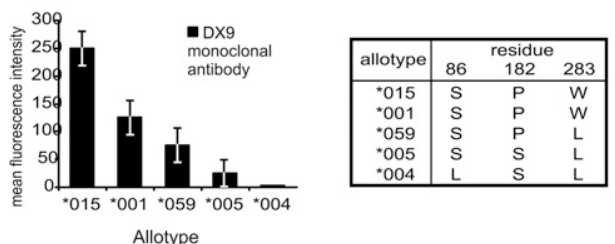

B
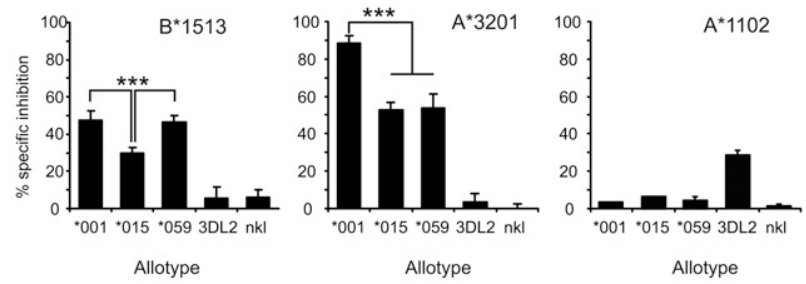

C
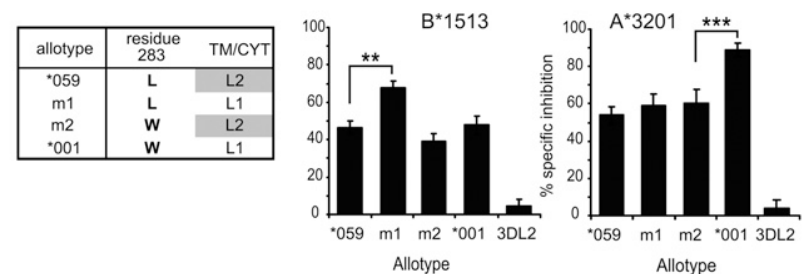

Figure 3. $3 D L 1 / 2 v$ mediates HLA-allotype specific inhibition of NK cells. (A) Binding of the 3DL1-specific monoclonal antibody DX9 to NK cells shows that $3 D L 1 / 2 v$ is expressed at the cell surface at intermediate level. Shown are FACS analyses of peripheral-blood NK cells from donors who express single 3DL1 allotypes. (Right) The table shows amino acid differences that correspond to the $3 D L 1$ expression level. $3 D L 1 * 004$ is not expressed because of leucine-for-serine substitution at residue 86 (Pando et al. 2003). 3DL1*015 has further differences in D0 that are shown in Figure 1. Error bars indicate the standard deviation of DX9-PE fluorescence intensity, from all of the lymphocytes that stained positive with DX9. $(B, C)$ Results from $\mathrm{Cr}^{51}$-release cytotoxicity assays. The basis for this assay is killing of HLA Class I-deficient cells (221) by an NK cell line (NKL). Inhibition of cytotoxicity occurs if NKL is transduced with inhibitory KIR and 721.221 is transfected with cognate HLA Class I ligand. Blocking the interaction with specific antibody restores target killing to that obtained using nontransduced NKL. The specificity of inhibition was determined in replicate assays using DX9, which specifically blocks 3DL1, or DX31, which specifically blocks 3DL2. The percent specific inhibition that is shown was calculated from killing in the presence of control/specific-blocking antibody. Results are mean ( \pm SE) of five experiments at an effector:target ratio of 20:1. $\left({ }^{* * *}\right) P<0.001 ;\left(^{* *}\right) P<0.01$ from Student's $t$-test for comparison of means. All of the effectors killed HLA-negative targets. Each of these assays shows different combinations of KIR and ligand. (B) The degree of inhibition mediated by natural KIR allotypes; these are 3DL1*001, 3DL1*015, 3DL1/2v (3DL1 $\left.{ }^{*} 059\right)$, and $3 \mathrm{DL} 2{ }^{*} 001$ or no KIR (nkl). Target cells were 721.221 cells transfected with (left) HLA-B*1513, (center) $A^{\star} 3201$, and (right) $A^{\star} 1102$. $B^{\star} 1513$ and $-A^{*} 3201$ are ligands for 3DL1, and $A^{*} 1102$ is a ligand for 3DL2. (C, left) The table shows the composition of the mutant KIR allotypes. Tailswap mutant $\mathrm{m} 1\left({ }^{*} 001-\mathrm{L} 283\right)$ has the $3 \mathrm{DL} 1{ }^{*} 059$ Ig-domain with a 3DL1*001 tail. $\mathrm{m} 2\left({ }^{*} 059-\mathrm{W} 283\right)$ has the $3 \mathrm{DL} 1{ }^{*} 001$ lg-domain with a $3 D L 2 * 001$ tail. Results of the cytotoxicity analysis are shown for (center) HLA-A*3201 and (right) HLA-B*1513.

dimorphism at position 283 affects 3DL1 function. Substitution of tryptophan for leucine at position 283 increased the inhibitory signal on binding to $A^{*} 3201$ but decreased the response to $B^{*} 1513$ (Fig. 3C). For $3 \mathrm{DL} 1{ }^{*} 059$, the trend was similar-tryptophan 283 favored interaction with $A * 3201$, leucine 283 its interaction with $\mathrm{B}^{\star} 1513$ - but the difference was smaller. Thus a potential advantage of the recombinations that change residue 283 is that they 


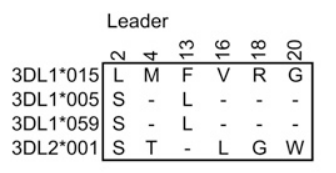

Do
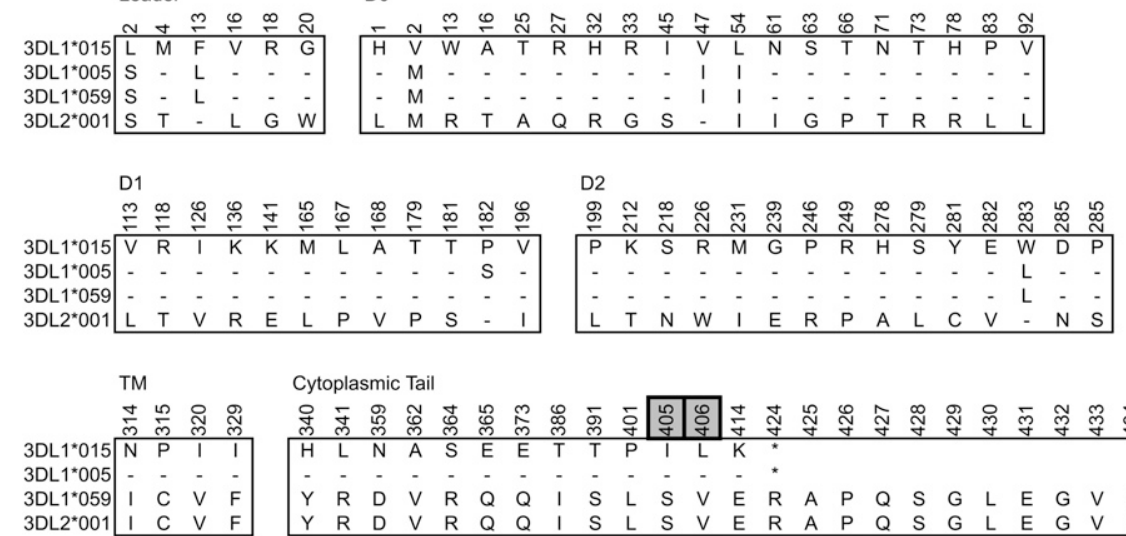

Figure 4. KIR3DL1 and KIR3DI2 differ at 68 amino acid residues spread throughout the polypeptide. Shown are the amino acid differences that distinguish 3DL1, 3DL2, and 3DL1/2v (3DL1*059). (Gray boxes) Differences that occur in the second ITIM motif of the cytoplasmic tail. Residue numbers are those of the mature protein. The $3 D L 1 * 059$ sequence that was independently obtained from CDNA (Shilling et al. 2002) is identical to the amino acid sequence encoded by the $3 D L 1 / 2 v$ gene characterized here (Fig. 1).

can increase the compatibility of 3DL1/S1 with the particular Bw4bearing HLA-A and HLA-B allotypes present in a population.

\section{Gene duplication by unequal crossing over allows individuals to carry all three 3DL1/S1 lineages}

The three lineages of 3DL1/S1 alleles (3DL1-005, 3DL1-015, and 3DS1) have been maintained by balancing selection for more than 3 million years (Norman et al. 2007). However, most individuals carry only one or two of the three lineages. Family studies identified a KIR haplotype in Europeans that contains both 3DS1 and $3 D L 1$ and likely was formed by unequal crossing over, which duplicated both the KIR2DL4 and 3DLl/S1 genes (Martin et al. 2003; Williams et al. 2003; Gomez-Lozano et al. 2005). The potential benefit to such duplication haplotypes is that they permit some individuals to carry all three $3 D L 1 / S 1$ allelic lineages. To assess the prevalence of the duplication haplotype, we used a newly developed pyrosequencing method that detects $3 D L 1 / S 1$ copy-number variation (Fig. 5) to study a panel of 2800 ethnically diverse blood donors. Eighty individuals $(2.9 \%)$ were demonstrated to have a KIR haplotype with two copies of 3DL1/S1 (Fig. 6A). By genotyping these individuals for $2 D L 4,3 D L 1 / S 1$, and $3 D L 2$ alleles, we defined seven different duplication KIR haplotypes (Fig. 6B). Each duplication haplotype was differentially distributed; as a group, they are most common in South and East Asians, with frequencies up to $10 \%$, less common in Caucasians, rare in Africans, and absent from Amerindians. Among the 80 individuals carrying a duplication haplotype, 23 of them (28.8\%) carried one allele from each of the three KIR3DL1/S1 lineages.

All seven duplicated haplotypes have the same general structure, containing two copies of $2 D L 4$ and 3DL1/S1 (Supplemental Fig. S5). Common to the seven haplotypes are the $2 D L 4^{*} 005$ and $3 D S 1{ }^{*} 01301$ alleles; these are associated with three other 2DL4 alleles, four 3DL2 alleles, and seven different $3 D L 1$ alleles embracing both $3 D L 1$ lineages and their full ranges of functional diversity. Each duplication haplotype contains a pair of $3 D L 1$ and 3DL2 alleles that are common and in linkage disequilibrium in the populations where the duplication haplotypes are present (Norman et al. 2004; Middleton et al. 2007). This property, combined with the constancy of $2 D L 4^{*} 005$ and $3 D S 1^{*} 01301$, supports an evolutionary model in which all the duplication haplotypes originated with a single event of unequal crossing over (Fig. 6A), which was subsequently followed by six independent events of homologous recombination that diversified the $3 D L 1$ and $3 D L 2$ genes of the duplication haplotype. The restricted geographical distribution of the duplication haplotypes, largely outside of Africa, and the linkage disequilibrium of their $3 D L 1$ and $3 D L 2$ genes point to the emergence of the duplication haplotypes during the last $60,000 \mathrm{yr}$, and since humans left Africa to populate Europe and Asia (Campbell and Tishkoff 2008).

We identified a family in which a son inherited a duplicated haplotype containing $3 D S 1^{*} 01301$ and $3 D L 1{ }^{*} 002$ from his mother. He inherited a second copy of $3 D S{ }^{*} 01301$ from his father (Fig. 6C). Using the monoclonal antibodies DX9, specific for KIR3DL1, and $\mathrm{Z} 27$ that binds much more strongly to 3DL1 than to 3DS1 (O'Connor et al. 2007; Trundley et al. 2007), we determined 3DL1/ $\mathrm{S} 1$ expression by the peripheral blood NK cells of members of this family. The frequency of NK cells expressing 3DS1 in the son $(50.5 \%)$ was more than the sum $(47.5 \%)$ of those cells in the mother (24.2\%) and father (23.3\%) (Fig. 6C). This indicates that both $3 D S 1{ }^{*} 013$ alleles inherited by the son are expressed by NK cells. The son also expressed $3 D L 1{ }^{*} 002$ on $6.8 \%$ of his NK cells, consistent with previous observation that this allele is usually expressed at low frequency by NK cells (Chan et al. 2003). Thus, each of the son's three KIR3DL1/S1 alleles is expressed by NK cells. A second son, who inherited two different KIR haplotypes from the parents, had no 3DS1-expressing NK cells and exhibited a bimodal distribution of cells with high-expressing $3 \mathrm{DL} 1{ }^{*} 015$ inherited from the mother and low-expressing 3DL1*007 inherited from the father (Fig. 6C). Although the mother's NK cells showed a high expression of 3DL1, we could not ascertain whether both $3 \mathrm{DL} 1{ }^{*} 002$ and $3 \mathrm{DL} 1{ }^{*} 1502$ were expressed, because they cannot be distinguished using available monoclonal antibodies. Two unrelated donors carrying alleles of each 3DL1/S1 lineage $-3 D S 1{ }^{*} 01301$ (3DS1 lineage), $3 D L 1{ }^{*} 00501$ (005 lineage) and $3 D L 1{ }^{*} 002$ or $3 D L^{*} 01502$ (015 lineage)-were therefore identified. Because $3 \mathrm{DL} 1{ }^{*} 005$ and $3 \mathrm{DL} 1{ }^{*} 015$ are readily distinguished by their low and high binding to Z27, respectively, we could demonstrate that all three alleles were expressed by subsets of NK cells in these individuals (Fig. 6D). In conclusion, individuals carrying three $3 D L 1 / S 1$ alleles representing the three allelic lineages express all three allotypes as NK cell receptors.

\section{Discussion}

NK cells provide an early defense against infection, particularly viral infections (Lanier 2008), and at an early stage in reproduction, they remodel maternal blood vessels that provide the fetus with nutrients via the placenta (Moffett and Loke 2006). In performing these functions, NK cell receptors have become highly diverse, rapidly evolving and largely species-specific (Kelley et al. 2005). Unlike the B-cell and T-cell receptors that diversify function

\section{Genome Research} www.genome.org 
through somatic recombination and mutation, NK cell receptors can only diversify through meiotic mutation and recombination. And in general, immune system genes have become more diversified by meiotic recombination than other functional types of human gene (Redon et al. 2006; Frazer et al. 2007) and display greater variation as assessed by copy number and segmental insertion/deletions (Dumas et al. 2007; Korbel et al. 2007).

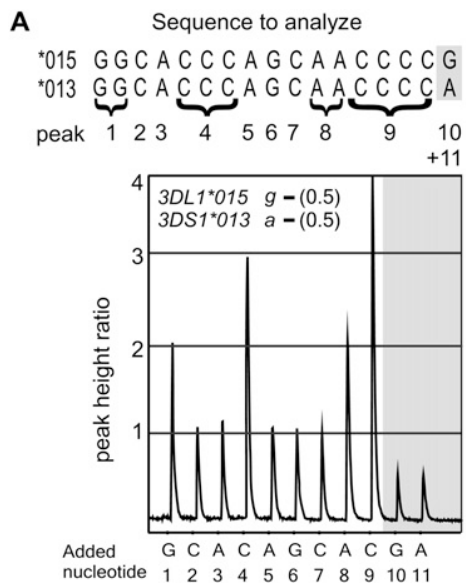

B

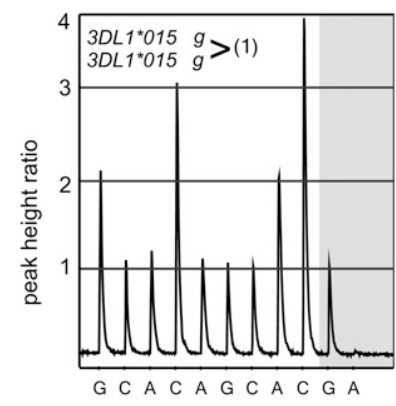

C

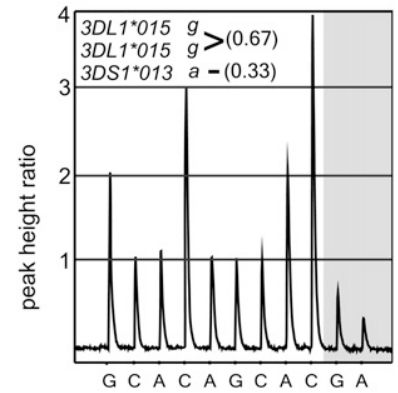

D

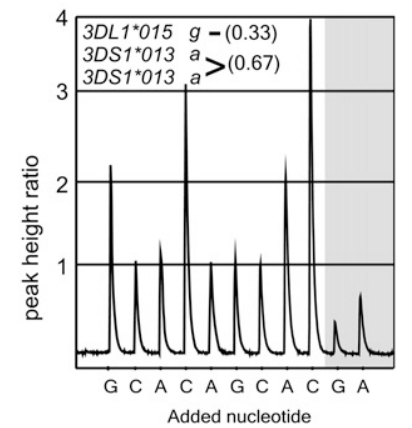

The state of the killer cell immunoglobulin-like receptor $(K I R)$ locus in the leukocyte receptor complex $(L R C)$ varies dramatically between species. In some, like the seals, it is a single conserved and nonpolymorphic gene, and in others, such as the dog, it appears to have been deleted (Hammond et al. 2009). In contrast, in the higher primates, the KIR locus has evolved to become a diverse multigene family encoding MHC Class I receptors (Khakoo et al. 2000; Rajalingam et al. 2004; Sambrook et al. 2005; Guethlein et al. 2007). On the basis of current information, KIR diversity appears greatest in the human species, where the combined effects of genecontent diversity and allelic polymorphism are such that unrelated individuals have distinct KIR genotypes (Shilling et al. 2002). The extent of KIR genotype variability approaches that of $H L A$ class I, with the functionally important combination of KIR and HLA genotypes being even more diverse (Parham 2005). Unequal crossing over is the likely mechanism that expanded the primate $K I R$ locus from its origin as a single-copy gene, and it is clearly implicated in the diversification of gene content in the modern human KIR haplotypes (Khakoo et al. 2000; Wilson et al. 2000; Martin et al. 2003). Further diversity is generated by homologous recombination, in particular, by the reassortment of allelic and gene-content motifs in the centromeric and telomeric parts of the locus (Wilson et al. 2000; Norman et al. 2004; Parham 2005). Here we have explored the role that meiotic recombination has played in the diversification of an individual human KIR gene, KIR3DL1/ $S 1$. This gene encodes highly polymorphic NK cell receptors that recognize HLA-A and HLA-B, the most polymorphic MHC genes.

Balancing selection and coevolution with HLA are consistently recognized features of the KIR (Hiby et al. 2004; Norman et al. 2004; Gendzekhadze et al. 2006; Single et al. 2007; Yawata et al. 2008). One of the strongest indicators for balancing selection is the long-term preservation of alleles without fixation or loss (Kimura and Ota 1969); another is the retention of alleles through periods of restricted population size. The $3 D L 1 / S 1$ locus comprises three ancient lineages of alleles that have been maintained by balancing selection over more than 3 million years and are present in all modern human populations (Norman et al. 2007), despite severe bottlenecks for some (Hey 2005). Contrasting with the conservation of the 3DS1 lineage, the 3DL1-005 and 3DL1-015

Figure 5. Simultaneous detection of $K I R 3 D L 1 / S 1$ polymorphism and copy-number using pyrosequencing. ( $A$, top) The diploid sequence of a 17-bp fragment of exon 3 from an individual heterozygous for $3 D L 1 * 01502$ and $3 D S 1 * 01301$. (Gray) SNP g336a. Underneath is a pyrogram obtained from the same individual. To generate the pyrogram, nucleotides were added to a single-strand template in the sequence shown, 1-11, and correspond to peaks of the same number. The peak height is proportional to the quantity of nucleotides that were incorporated, as shown by peak 1 (the sequence is $\mathrm{gg}$ ), which is twice the height of peak $6(\mathrm{~g})$. Each peak is a sum of the haplotypes present, so that the monomorphic positions (relative peak height $=1$ ) are used for calibration. The combined peak height at the heterozygous position shown (peaks $10+11$ ) is equal to the peak from a single monomorphic position. Shown are four different pyrograms; (top left of each diagram) the derived genotype; (brackets) the peak-height ratio compared with the single monomorphic peak. (A) At SNP $g 336 a$, there is one peak for $g$ and one for $a$ (peaks 10 and 11), and each peak is half the height of a single peak (peak 6). This individual has one copy of $3 D L 1 * 01502$ and one copy of $3 D S 1{ }^{*} 01301(0.5 \mathrm{~g}: 0.5 a)$. (B) At SNP $g 336 a$, there is one peak for $g$ (peak 10) that is the same height as a single monomorphic position (peak 6 ) and no peak on addition of nucleotide $a-11$. This individual is homozygous, having two copies of $3 D L 1 * 01502(1 \mathrm{~g}: 0 \mathrm{a})$. (C) There are two peaks as for $A$, but $g$ is twice the height of $a(0.67 \mathrm{~g}: 0.33 \mathrm{a})$, and their sum is the same as peak 6. This individual has two copies of $3 D L 1{ }^{*} 01502$ and one $3 D S 1 * 01301$. (D) This individual has one copy of $3 D L 1 * 01502$ and two of $3 D S 1{ }^{*} 01301(0.33 \mathrm{~g}: 0.67 a)$. 
A KIR3DL3 2DS2 2DL2 2DL3 2DL1 2DL5B 2DS3 3DP1 2DL4 3DL1/S1 2DL5A 2DL4 3DL1/S1 2DS5 2DS1 2DS4 3DL2

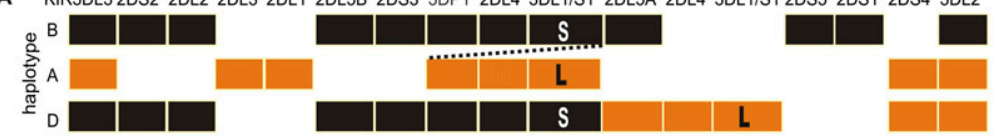

B
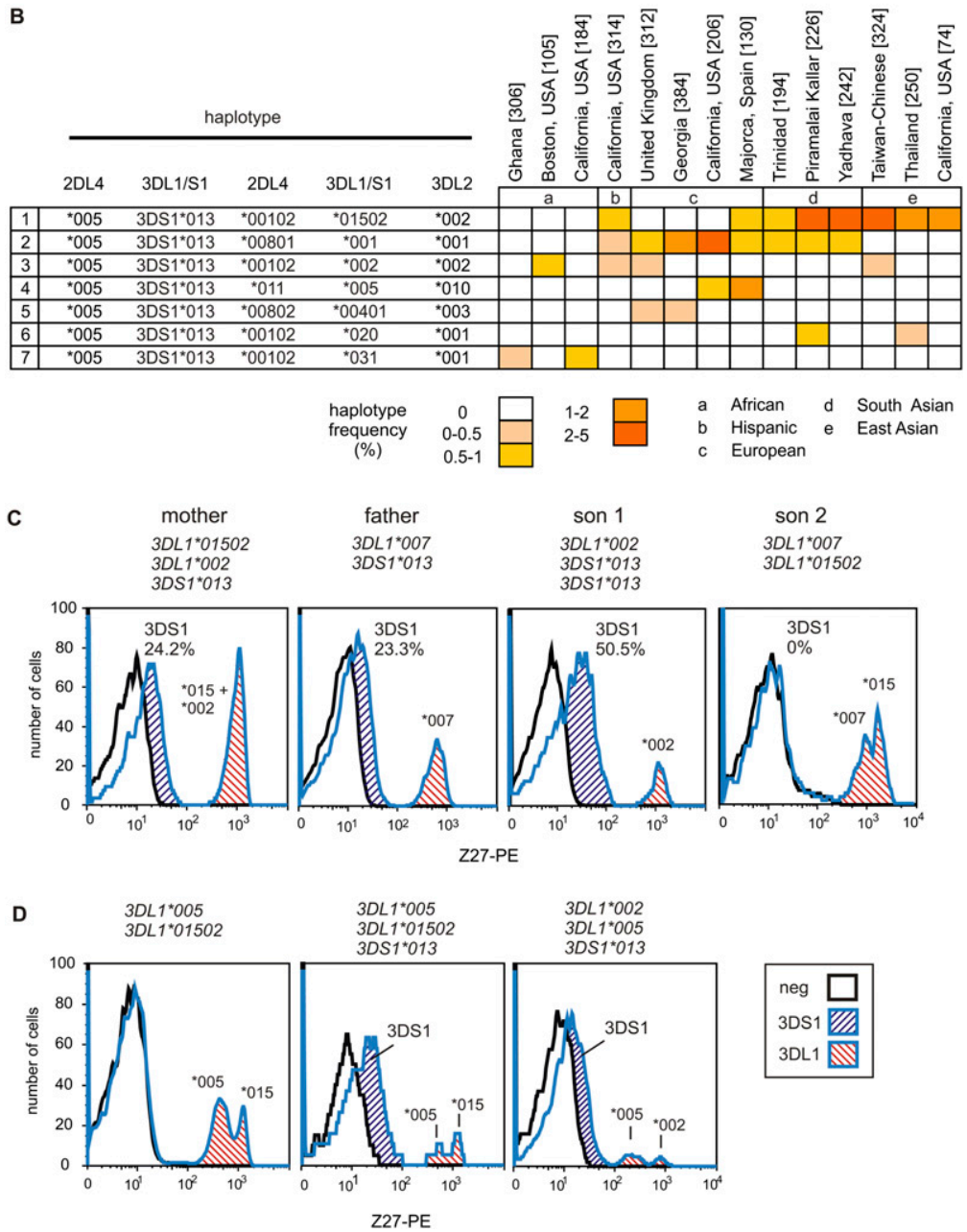

Figure 6. Duplicating KIR loci diversifies the NK cell repertoire in quantity and quality. ( $A$ ) Schematic of the donor haplotypes and duplication haplotype. (Across the top) The KIR loci; (shaded boxes) indicate presence of the locus. The donor KIR haplotypes B (black) and A (orange); the composite duplication haplotype $D$ is colored accordingly. (Dotted line) Non-allelic homologous recombination that was mediated by sequence similarity in the 5'-regions of 3DP1 and 2DL5A (Martin et al. 2003; GomezLozano et al. 2005). (B) The seven different 2DL4, 3DL1, and 3DL2 haplotypes deduced from analysis of 80 individuals who have the duplication, and their haplotype frequencies in the populations where they were detected. The number of haplotypes analyzed from each population is indicated in parentheses. Georgia is the country. The Piramalai Kaller and the Yadheva are two distinct populations from Tamil Nadu in Southern India. (C) Shown are FACS analyses of freshly isolated 3DL1/S1-expressing NK cells from a European family with a duplicate haplotype. (At the top of each plot) The pyrosequencing genotype. Son 1 inherited $3 D S 1 * 013$ and $3 D L 1 * 002$ (haplotype 3, panel $B$ ) from the mother and $3 D S 1{ }^{*} 013$ from the father. Monoclonal antibody Z27 discriminates 3DL1/S1 allotypes, having high $(3 D L 1 * 002$ and $3 D L 1 * 015)$, low $(3 D L 1 * 005$ and $3 D L 1 * 007)$, and very low $(3 D S 1 * 013)$ staining patterns. Showing that $3 D L 1 / S 1$ expression depends on the number of copies of 3DS1 present, Son 1 has twice the number of $3 \mathrm{DS} 1^{+} \mathrm{NK}$ cells as the mother or father. Son 2 has inherited the opposite pair of haplotypes to Son 1, and expresses two distinct populations of high $\left({ }^{*} 015\right)$ and low $\left({ }^{\star} 007\right)$ 3DL1 staining and no 3DS1. Further differences among allotypes are quantitative, with *015 being expressed by more cells than *002 (Chan et al. 2003), as observed here by comparing 3DL1 expression of the mother and Son 1. (D) Three unrelated individuals chosen for their 3DL1/S1 genotype. (Left) An individual heterozygous for $3 D L 1{ }^{*} 015$ and $3 D L 1 * 005$ is shown as a negative control for the very lowstaining 3DS1*013 peak. (Center and right) Two individuals who both express all three lineages of 3DL1/S1 receptors; these FACS analyses are from NK cells that had been stored frozen. A comparison of fresh and frozen NK cell staining is shown in Supplemental Figure S6. lineages of inhibitory receptors are now highly diverse. Of the approximately 60 alleles defined, 12 are recombinants, most of which have been formed by recombination or conversion between alleles from different lineages. Two main targets for recombination have been polymorphic motifs in the D0 domain, the enhancer that modulates the strength of the binding site formed by the D1 and D2 domains (Khakoo et al. 2002) and a dimorphism at position 283 in D2 that we show alters the strength of the inhibitory signal transduced upon binding of 3DL1 to Bw4.

Only the three lineage-defining $3 D L 1 /$ $S 1$ alleles-3DS1*01301, 3DL1*00501, and $3 D L 1{ }^{*} 01502$ - are common to all human populations, the vast majority of the others being specific to particular populations, geographical regions, and ethnic groups (Norman et al. 2007). Since humans originated in Africa and eventually went on to populate other continents (Goldstein and Chikhi 2002), unequal crossing over has produced novel recombinant alleles and haplotypes that mark particular populations. For example, the 3DL1*009 recombinant allotype, in which the D0 domain of $3 \mathrm{DL} 1{ }^{*} 015$ is replaced with that of $3 \mathrm{DS} 1^{*} 013$, is restricted to European and some South Asian populations (Middleton et al. 2007; Norman et al. 2007). That we consistently observe population stratification of $3 D L 1 / S 1$ alleles points to recent or ongoing selection for variation. Up to $10 \%$ of sub-Saharan African populations have a KIR haplotype that was formed within 0.74 million years by an unequal crossing over that caused the deletion of $>30 \mathrm{~kb}$ from the telomeric part of the KIR locus and created a novel hybrid gene, by fusing exons $1-5$ from $3 D L 1{ }^{*} 005$ with exons $7-9$ of the $3 D L 2^{*} 001$ gene. The fusion protein encoded by this $3 D L 1 / 2 \mathrm{v}$ allele $\left(3 D L 1^{*} 059\right)$ combines the extracellular, Ig-like domains of $3 \mathrm{DL} 1{ }^{*} 005$ with the transmembrane and cytoplasmic domains of $3 \mathrm{DL} 2 * 001$. As expected, $3 \mathrm{DL} 1{ }^{*} 059$ has specificity for Bw4, but it has a more even response to HLA-A and HLA-B allotypes having the Bw4 epitope, and transduces a weaker inhibitory signal, than other 3DL1 allotypes. Since the formation of $3 \mathrm{DL} 1 * 059$ by recombination, subsequent point substitutions in the cytoplasmic tail produced $3 \mathrm{DL} 1{ }^{*} 060$ and $3 \mathrm{DL} 1{ }^{*} 061$ allotypes. Valine 384 that distinguishes $3 \mathrm{DL} 1{ }^{*} 061$ is close to an ITIM motif (Feng et al. 2005), and the substitution of cysteine for serine at

\section{Genome Research www.genome.org}


residue 394 in $3 \mathrm{DL} 1{ }^{*} 060$ that eliminates a protein kinase $\mathrm{C}$ phosphorylation site is predicted to increase inhibitory signals (Alvarez-Arias and Campbell 2007). Thus, the variants of 3DL1/2v have the potential for functional difference. That all hominoid KIR haplotypes have a lineage II gene with an exon 9 orthologous to that of $3 D L 2$, despite much recombination, points to the importance of the signaling domain it encodes (Rajalingam et al. 2001; Sambrook et al. 2005; Guethlein et al. 2007).

Gene fusion is a recognized means for generating genetic novelty (Bailey and Eichler 2006), but to our knowledge, 3DL1/2v is the first demonstration of the phenomenon occurring in humans. Among the 600 gene fusions described for eukaryotes (Kummerfeld and Teichmann 2005), all those identified as human-specific are associated with disease or abnormality. One possible exception is the family of $\mathrm{X}$ chromosome gene fusions of OPN1MW/LW that cause anomalous color detection in males (Nathans et al. 1986), but may benefit female carriers (Deeb 2006). As shown for other SNPs at these loci, heterozygous females have enhanced color discrimination (Jameson et al. 2001).

Whereas the unequal crossing over that produced $3 D L 1 / 2 v$ reduced the size of a KIR haplotype, in Eurasia a different event of unequal crossing over served to duplicate the $3 D L 1 / S 1$ locus such that the haplotype had one copy of $3 D S 1$ and one copy of $3 D L 1$. Subsequent events of reciprocal crossing over have diversified this duplicated haplotype so that at least seven different 3DL1 alleles, including most of the more common alleles of both the 005 and 015 lineages, are associated with $3 D S 1^{*} 013$. Although we do not know which $3 D L 1$ allele was present on the original duplicated haplotype, that containing $3 D L 1{ }^{*} 01502$ appears the most prevalent.

When first characterized from cDNA, 3DL1 and 3DS1 were assigned to different loci based on the divergent sequence and function of their transmembrane and cytoplasmic domains (Robinson et al. 2006). Subsequent family and population studies showed that 3DL1 and 3DS1 usually segregate as alleles (Middleton et al. 2007), and sequence comparison indicated that 3DS1 was formed from $3 D L 1$ by recombination with a gene encoding an activating KIR (Rajalingam et al. 2004). Consequently, 3DS1 and $3 D L 1$ are generally considered to be alleles of a single locus: $3 D L 1 / S 1$. The duplicated haplotypes are exceptional because they have two genes of which one is always 3DS1 and the other is always $3 D L 1$. So far no duplicated haplotype containing two copies of 3DL1 and only one with two copies of 3DS1 (Gomez-Lozano et al. 2005) have been identified, indicating that such recombination is rare or that such events are selected against. Thus within the context of the duplicated haplotypes 3DS1 and 3DL1 are two different genes. This illustrates a more general complexity of the KIR system, namely, imprecision or blurring in the distinction between loci and alleles. At the KIR, MHC, and other immunological loci, an understanding of the synergy between allelic polymorphism and copy-number variability that generates diversity has required intensive, focused analysis (Bergstrom et al. 1999; Chung et al. 2002; Hollox et al. 2008). To determine the extent to which the findings apply to other gene families will require analyses of similar commitment and intensity (Dumas et al. 2007; Perry et al. 2008).

Throughout human history, balancing selection has maintained the 3DS1, 3DL1-005, and 3DL1-015 lineages of alleles. Today, the only three KIR3DL1/S1 alleles present in all the populations studied are $3 D S 1{ }^{*} 01301,3 D L 1{ }^{*} 00501$, and $3 D L 1{ }^{*} 01502$. This observation indicates that the three lineages have distinct and complementary functions that have facilitated the survival and propagation of human populations, a corollary being that populations that lost a $3 D L 1 / S 1$ lineage failed to compete and survive over the long term. Despite the benefit of three allelic lineages for populations, most modern humans carry alleles from only one or two $3 D L 1 / S 1$ lineages and suffer no obvious disadvantage in either survival or reproduction. In this context, the potential advantage of the duplicated KIR haplotype is that it is a mechanism by which individuals can carry all three $3 D L 1 / S 1$ lineages and, as we have shown, express them as NK cell receptors. In sub-Saharan African populations, the balance between the three $3 D L 1 / S 1$ lineages appears to have given way to selection for the 3DL1-015 lineage and against the 3DS1 and 3DL1-005 lineages (Norman et al. 2007). A further characteristic of sub-Saharan Africans is that a significant proportion of the 3DL1-005 lineage allotypes is $3 \mathrm{DL} 1{ }^{*} 059,3 \mathrm{DL} 1{ }^{*} 060$, and $3 \mathrm{DL} 1{ }^{*} 061$, products of the gene fusion between $3 D L 1{ }^{*} 005$ and $3 D L 2$. Selection for these alleles, might also reflect selection against conventional $3 D L 1 * 005$ and for the modified functions imposed on its extracellular domains by the distinctive transmembrane and cytoplasmic domains of 3DL2.

KIR3DL1 and 3DL2 that recognize determinants of HLA-A and -B are encoded by lineage II KIR genes, which are represented in hominoid species by two or more genes. Exceptional is the chimpanzee, which has one lineage II KIR gene (Pt-KIR3DL1/2) that encodes a protein with structural and functional similarities to both 3DL1 and 3DL2. In chimpanzee KIR haplotypes, Pt-KIR3DL1/2 is the only gene on the telomeric side of Pt-KIR2DL4, an arrangement like that of the human haplotypes containing $3 D L 1 / 2 v\left(3 D L 1{ }^{*} 059\right.$, $3 D L 1^{*} 060$, and $\left.3 D L 1^{*} 061\right)$ in which $3 D L 1$ and $3 D L 2$ have been reduced to a single fusion gene. We have shown that the similarities of $3 D L 1 / 2 v$ and Pt-KIR3DL1/2 are not due to common ancestry but to convergence, further emphasizing the dynamic nature of the KIR gene family and continuing cycles of gene expansion and contraction through meiotic recombination.

\section{Methods}

\section{Subjects}

The subjects studied here are as described by Norman et al. (2007). Blood samples were collected and the research conducted with approval from the appropriate Institutional Review Boards. The two Tanzanian populations are from (1) a village that lives on the coastal plain near the Indian Ocean and (2) a village at an altitude of $1700 \mathrm{~m}$ in the West Usambara Mountains.

\section{KIR nomenclature}

KIR genes and alleles were named by the KIR Nomenclature Committee (Marsh et al. 2003), formed from the WHO Nomenclature Committee for factors of the HLA system and the HUGO Genome Nomenclature Committee. A curated database is available at http://www.ebi.ac.uk/ipd/kir/ (Robinson et al. 2006). $\langle$ D $>$ denotes the number of Ig-like Domains; $<\mathrm{L}>$ a Long, inhibitory, cytoplasmic tail; $\langle\mathrm{S}>$ a Short, activating, tail; and $<\mathrm{P}>$ a Pseudogene. For each locus, the alleles are named in the order of their discovery, with the first three digits distinguishing alleles encoding different proteins. The second two digits are used to indicate synonymous variation. As an example, KIR3DL1*01501 and KIR $3 D L 1{ }^{*} 01502$ are synonymous variants of the $3 D L 1{ }^{*} 015$ allele, and both encode the 3DL ${ }^{*} 015$ allotype-an inhibitory receptor having three Ig-like domains. When the meaning is unambiguous, KIR or even KIR3DL1 can be dropped from allele names. 


\section{PCR/DNA sequencing}

PCR was performed using a Perkin-Elmer 9600 thermal cycler with a 3-min denaturing step at $94^{\circ} \mathrm{C}, 10$ cycles of $\left(10 \mathrm{sec}\right.$ at $94^{\circ} \mathrm{C} ; 60 \mathrm{sec}$ at $\left.65^{\circ} \mathrm{C}\right)$ and $20 \mathrm{cycles}$ of $\left(10 \mathrm{sec}\right.$ at $94^{\circ} \mathrm{C}, 50 \mathrm{sec}$ at $61^{\circ} \mathrm{C}, 30 \mathrm{sec}$ at $72^{\circ} \mathrm{C}$ ). When the expected amplicons were $>3.5 \mathrm{~kb}$, long rangePCR (LR-PCR) was performed using TripleMaster/HiFi reagents (Eppendorf) and the oligonucleotide primers described in Supplemental Figure S2. LR-PCR conditions were $3 \mathrm{~min}$ at $94^{\circ} \mathrm{C}$ followed by 28 cycles of $\left(20 \mathrm{sec}\right.$ at $94^{\circ} \mathrm{C}, 10 \mathrm{sec}$ at $61^{\circ} \mathrm{C}, 4 \mathrm{~min}$ at $\left.68^{\circ} \mathrm{C}\right)$ completed with $15-\mathrm{min}$ extension at $68^{\circ} \mathrm{C}$. Products were cloned using the pCR 2.1-TOPO vector (Invitrogen) and sequenced using internal primers. Standard DNA sequencing was performed in forward and reverse directions using BigDye Terminator v3.1 and analyzed using an ABI-377 sequencer (ABI). Three clones of the desired allele were sequenced from each individual.

\section{Characterizing the $K I R 3 D L 1 / 2 v$ gene sequence}

The KIR3DL1/2v gene sequence was characterized from one donor using multiple PCR primer pairs (Supplemental Fig. S7) and from four donors using six overlapping PCR fragments that spanned the haplotype from 2DL4 to FCAR (Supplemental Fig. S2). The four donors were selected to represent all three different $3 D L 1 / 2 v$ sequences and also to have a distinct second KIR haplotype. Unambiguous sequence data were generated from one of the donors, who is hemizygous for $3 D L 1 / 2 v$ so has no second $3 D L 1 / S 1$ allele (Supplemental Fig. S2). For each heterozygous individual, sufficient SNPs were present to distinguish two haplotypes upon cloning, except for two of the reactions that were allele-specific (bands A and C) (Supplemental Fig. S2). Each amplicon was cloned using pCR 2.1 and sequenced in triplicate for each allele present. All of the PCR primers were designed to be KIR gene- or allelespecific (Supplemental Fig. S2; Supplemental Table S1). Accession numbers for the newly generated $3 D L 1{ }^{*} 059-61$ genomic DNA sequences are EU267269-71 and FJ459734.

The $3 D L 1 / S 1{ }^{*} 059$ donor was an African-American from California (genotype: $3 D L 1{ }^{*} 031,3 D L 1{ }^{*} 059,3 D L 2{ }^{*} 001$ ). The $3 D L 1 /$ $S 1{ }^{*} 060$ donor was an African from Nigeria (genotype: $3 D L 1{ }^{*} 035$, $\left.3 D L 1{ }^{*} 60,3 D L 2{ }^{*} 001\right)$. The $3 D L 1 / S 1 * 061$ donor was an AfricanAmerican from California (genotype: $3 D L 1{ }^{*} 040,3 D L 1{ }^{*} 061$, $3 D L 2{ }^{*} 010$ ). The hemizygous donor was an African from Nigeria who has a KIR haplotype that lacks $3 D P 1,2 D L 4$, and 3DL1/S1 but retains 3DL2 (Norman et al. 2004). This individual has one 3DL1/ $S 1$ allele and one $3 D L 2$ allele (genotype: $3 D L 1{ }^{*} 059,3 D L 2{ }^{*} 006$ ).

\section{DNA sequences and recombination analysis}

Recombinant sequences were identified from a domain-bydomain phylogenetic analysis. Gene conversion was identified using RDP (Recombination Detection Programs) version 2 (Martin et al. 2005) with a sliding window of $20 \mathrm{bp}$, with Bonferroni correction and a threshold of $P=0.001$. Coding sequences of $3 D L 1 / S 1$ used for alignments were obtained from the IPD database (http:// www.ebi.ac.uk/ipd/kir/index.html) (Robinson et al. 2006) and those described in Belle et al. (2008) and Thomas et al. (2008). cDNA from $3 D S{ }^{*} 050$ (EF582383) was fully characterized here using methods previously described (Shilling et al. 2002). Genomic DNA sequences that spanned exons 1-5 (encoding the extracellular domains) and exons 7-9 (encoding the cytoplasmic domain) were characterized by LR-PCR from the following alleles: $3 D L 1{ }^{*} 001,3 D L 1{ }^{*} 00501,3 D L 1{ }^{*} 009,3 D L 1{ }^{*} 01501,3 D L 1{ }^{*} 022$, $3 D L 1{ }^{*} 029,3 D L 1{ }^{*} 030,3 D L 1{ }^{*} 031,3 D L 1{ }^{*} 035,3 D L 1{ }^{*} 036$, and $3 D L 1{ }^{*} 040$ (GenBank: FJ158650-60). 3DS1*01301 and 3DL2*007 sequences were extracted from AL133414 (3DS1a) (Wilson et al. 2000) and AY320039 (3DS1b). A second $3 D L 1{ }^{*} 001$ genomic sequence, and $2 D L 4^{*} 00801$ and $3 D L 2{ }^{*} 001$ were obtained from AC011501 (Wilson et al. 2000). For the analysis indicated in Supplemental Figure 3B, a further $2 \mathrm{~kb}$ of sequence that surrounds the crossover point in intron 5 was obtained from $3 D L 1{ }^{*} 00501$, $3 D L 1{ }^{*} 01501$, and $3 D L 1{ }^{*} 040$; for $3 D L 1{ }^{*} 002$ the equivalent sequence was obtained from CU151839 and $3 D L 22^{*} 010$ from CU464063 (Horton et al. 2006). pt2DL4 and pt3DL1/2 genomic DNA sequence was obtained from BX842589 (Sambrook et al. 2005) and Popy2DL4 and Popy3DLa from EF014479 (Guethlein et al. 2007).

\section{DNA sequence analysis}

Nucleotide sequences were aligned using ClustalX (Thompson et al. 1997) and BioEdit (www.mbio.ncsu.edu/BioEdit/bioedit. html). Neighbor-joining phylogenetic analyses were conducted using the Tamura-Nei method of MEGA3.1 and 500 bootstrap replicates (Kumar et al. 2004). PAML was used to reconstruct the ancestral sequences at specified nodes, using the marginal reconstruction method and the M8 model (Yang 2007).

\section{Divergence time estimations}

Divergence times were estimated using the MCMCTREE program from PAML 4 (Yang 2007), which uses Markov-chain Monte Carlo analysis for estimating mean posterior divergence times and their $95 \%$ credibility interval (CI). The Markov chain was sampled 5000 times every 10 cycles, and the burn-in stage was set to 5000 cycles. MODELTEST 3.7 (Posada and Crandall 1998) was used to gauge the nucleotide-substitution model (HKY95) and the $\alpha$-distribution of this substitution ( 0.83 and 1.03 for the sequences 5 ' and 3 ' from the $3 D L 1 / 2 v$ crossover, respectively). Calibration points were set according to fossil data and the divergence times: $\mathrm{CI}=23-33$ Mya for macaque/hominoid, CI = 10-18 Mya (mean 12) orangutan/ hominid, and CI = 6-8 Mya (mean 7) for chimpanzee/hominid (Benton and Donoghue 2007).

\section{Genotyping by pyrosequencing}

Using primers described in Supplemental Table 1, individual exons from $2 D L 4$ and $3 D L 2$ were amplified and subjected to pyrosequencing. Exon-specific PCR was performed using a Perkin-Elmer 9600 thermal cycler with a 3-min denaturing step at $94^{\circ} \mathrm{C}, 10$ cycles of $\left(10 \mathrm{sec}\right.$ at $94^{\circ} \mathrm{C}, 60 \mathrm{sec}$ at $\left.65^{\circ} \mathrm{C}\right)$, and 20 cycles of $\left(10 \mathrm{sec}\right.$ at $94^{\circ} \mathrm{C}$, $50 \mathrm{sec}$ at $61^{\circ} \mathrm{C}, 30 \mathrm{sec}$ at $72^{\circ} \mathrm{C}$ ). Identical conditions were used for a second specific reaction but with 35 cycles in the final step. Samples were purified using strepdavidin-coated Sephadex beads, and pyrosequencing reactions were performed using the Pyro-Gold reagents and a PSQ96A machine fitted with Capillary Dispensing Tips (Biotage Ltd.). 3DL1/S1 genotyping was performed as described (Norman et al. 2007). The genotyping procedures were performed in parallel with previously described family and control samples (Gardiner et al. 2001; Shilling et al. 2002; Artavanis-Tsakonas et al. 2003; Norman et al. 2004, 2007). To further validate the techniques, a random selection of $25 \%$ donors was also re-sequenced from a freshly generated amplicon. According to the most recent sequence alignments (http://www.ebi.ac.uk/ipd/kir/index.html), the combination of techniques discriminates $112 D L 4$ alleles, 52 3DL1/ $S 1$ alleles, $223 D L 2$ alleles, three $3 D L 1 / 2 v$ alleles, and copy-number variation for each locus.

\section{Detection of $K I R 3 D L 1 / 2 v$ by genotyping 3DL1/S1 and 3DL2}

Because no SNP uniquely defines the $3 D L 1 / 2 v$ sequences, the pyrosequencing protocol was designed to detect a unique 
combination of SNPs in exons 1-5 that distinguishes $3 D L 1 / 2 v$ from $3 D L 1 / S 1$ (Fig. 1$)$. Three different $3 D L 1 / 2 v$ alleles $\left(3 D L 1{ }^{*} 059\right.$, $\left.3 D L 1{ }^{*} 060,3 D L 1{ }^{*} 061\right)$ were distinguished by one further SNP in exon 5 and two SNPs in exon 9. At the cDNA level, $3 D L 1{ }^{*} 059$ (Shilling et al. 2002) and $3 D L 1{ }^{*} 060$ (Artavanis-Tsakonas et al. 2003) have been described previously, and $3 D L 1{ }^{*} 061$ was discovered during the present study. Two other $3 D L 1 / 2 v$ sequences reported previously (AY366254-5) were not observed in the present study. Heterozygosity was calculated using Arlequin (Schneider et al. 2000).

\section{Detecting copy-number variation using pyrosequencing}

Pyrosequencing uses enzyme-coupled reactions to generate light from the pyrophosphate molecules released upon DNA elongation (Ronaghi et al. 1996). Nucleotides are added sequentially so that the reaction proceeds only when the correct base is added. Light emission is plotted on a Pyrogram that has peak height proportional to the number of pyrophosphate molecules released. The technique is semiquantitative because the combined peak heights from a polymorphic position equal the height of the single peak at a monomorphic position (Fig. 5). With this method, we were able to determine the presence of three $3 D L 1 / S 1$ alleles in individuals having a duplication of the $3 D L 1 / S 1$ locus on one haplotype even when two of the alleles were identical in sequence, because peak-height ratios were 2:1 in favor of the allele present in two copies. All genotyping methods were designed so that each genotype gave a distinct pattern of several SNPs dispersed through the locus and did not rely on single marker SNPs. We were thus able to accurately assign three-copy genotypes by virtue of consistency in peak-height ratios throughout the locus.

To validate the copy-number detection method, two families shown previously by segregation analysis to have duplicated 3DL1/S1 (Martin et al. 2003; Norman et al. 2004) were used as standards. Furthermore, for eight of the 80 individuals in whom the duplication was detected, PCR products that span exons 3-5 of $2 D L 4$ were generated, cloned, and sequenced ( 12 clones) to verify the presence of three different $2 D L 4$ alleles and thus of the duplication. Some individuals may possess two copies of a $3 D L 1 / S 1$ duplicated haplotype, and if the $3 D L 1 / S 1$ pairs on the two haplotypes were identical, we would not have distinguished them from a normal heterozygote. However, the observed maximum frequency of $10 \%$ for duplicated-3DL1/S1 haplotypes implies that, assuming Hardy-Weinberg equilibrium, only one or two individuals from the entire cohort had two identical duplicated-3DL1/S1 haplotypes.

Haplotype composition and frequency were estimated in the following way: Allele phase was assigned per population by linkage disequilibrium using Arlequin (Schneider et al. 2000). Genotypes found in only one or two individuals were first compared with other populations of similar origin, and then with the entire sample set, to derive the most parsimonious interpretation. This approach was designed to estimate the minimum number of different haplotypes that could be distinguished based on the composition of $2 D L 4,3 D L 1 / S 1$, and $3 D L 2$ alleles. After such iterative deductions, the genotypes of only two individuals remained ambiguous. Fifty-one of the 80 individuals having a duplication haplotype were genotyped using locus-specific primers to determine their KIR locus genotype (Uhrberg et al. 1997).

\section{Flow cytometry}

Peripheral blood mononuclear cells (PBMC) were isolated on ficoll gradients. Monoclonal antibodies used for flow cytometry were CD3-PE-Cy5, CD56-FITC, 3DL1(DX9)-PE, and IgG1 isotype con- trols (all BD Biosciences) and 3DL1(Z27)-PE (Beckman Coulter). $\mathrm{CD}^{-}{ }^{-} \mathrm{CD} 56^{+} \mathrm{NK}$ cells were monitored for expression of 3DL1/S1 using DX9, which reacts with 3DL1, and Z27, which reacts with both 3DL1 and 3DS1 (Supplemental Fig. S6; Gardiner et al. 2001; Carr et al. 2007; Trundley et al. 2007; Thomas et al. 2008). Thus, NK cells from individuals carrying $3 D S 1$ and $3 D L 1$ give two peaks of Z27 staining, but only one peak of DX9 staining. 3DL1*004 is not expressed at the cell surface and binds neither antibody (Pando et al. 2003). Flow-cytometry data were analyzed using FlowJo software.

\section{Generation of NK effector and target cell lines}

Effector cells were NKL cells transduced to express wild-type and mutant 3DL1 allotypes. Full-length KIR cDNA sequences were amplified from PMBC and cloned into a pCR 2.1 vector (Invitrogen). Site-directed mutagenesis was performed using the QuikChange mutagenesis kit (Stratagene) according to the manufacturer's instructions. Full-length coding regions were then cloned into the pBMN retroviral vector and transferred by retrovirus to NKL cells. Recombinant retrovirus was generated by transfection into Phi-NX cells, supernatants were used to infect $\mathrm{NKL}$, and the cells were sorted for KIR expression level using a FACSVantage cell sorter (BD Biosciences), as previously described (Moesta et al. 2008).

Target cells were the Class I-deficient B-cell line 221 and transfectants of 221 expressing HLA allotypes: $A^{*} 1102, A^{*} 3201$, or $\mathrm{B}^{\star} 1513 . A^{*} 3201$ cDNA was obtained from the WT47 cell line. $A^{*} 1102$ cDNA was generated by site-directed mutagenesis of $A^{*} 1101$ cDNA, which had been obtained from the KT17 cell line. HLA-E can present peptides that are derived from the leader peptides of HLA Class I molecules and protect 221 cells from lysis, owing to interaction of HLA-E/peptide with the CD94/NKG2A inhibitory receptor that is expressed by NK cells (Braud et al. 1998). Recombinant PCR was used to replace the HLA-A leader peptide fragment with VMAPVTLLLLL; the R5V mutation (underlined) abrogates interaction of the HLA-E/peptide with CD94/NKG2A (Michaelsson et al. 2002). HLA Class I cDNA was transfected into 221 cells using pBJneo as previously described (Gumperz et al. 1995).

\section{NK cytotoxicity assays}

Standard chromium-release assays were used to assess the degree of inhibition conferred by specific 3DL1 allotypes. NKL cells expressing 3DL2*001 and 721.221 cells expressing HLA-A ${ }^{*} 1102$ were used as controls to investigate the specificity of $3 \mathrm{DL} 1 / 2 \mathrm{v}$ mediated inhibition. Two blocking agents were used in parallel experiments as controls: DX9 (anti-3DL1) was used to block the 3DL1/HLA interaction, and DX31 (anti-3DL2) was used to block the 3DL2/HLA-A11 interaction. Effector cells were mixed with ${ }^{51} \mathrm{Cr}$ loaded target cells for $4 \mathrm{~h}$ at $37^{\circ} \mathrm{C}$ at ratios ranging from $40: 1$ to $10: 1$. Following incubation, supernatants were harvested and ${ }^{51} \mathrm{Cr}$ was quantified using a Wallac $\beta$-scintillation counter. Percent specific lysis was calculated using the formula [(Specific Release Spontaneous Release)/(Total Release - Spontaneous Release) $\times$ 100]. Experiments were conducted in triplicate for each condition, and each experiment was repeated independently five times. Comparison of means at the 20:1 ratio was performed using the Student's $t$-test $(8 \mathrm{df})$.

\section{Complete list of author affiliations}

${ }^{1}$ Department of Structural Biology and Department of Microbiology and Immunology, Stanford University School of Medicine, 
Stanford, California 94305, USA; ${ }^{2}$ Department of Preclinical Sciences, Faculty of Medical Sciences, University of West Indies, St. Augustine, Trinidad and Tobago; ${ }^{3}$ Department of Transfusion Medicine, Faculty of Medicine and Siriraj Hospital, Mahidol University, Bangkok 10070, Thailand; ${ }^{4}$ School of Medical Laboratory and Biotechnology, Chung Shan Medical University, Taichung 402, Taiwan; ${ }^{5}$ Immunology Service, Hospital Universitari Son Dureta, Palma 07014, Spain; ${ }^{6}$ Istanbul Medical Faculty, Department of Physiology, Istanbul University, Istanbul 34093, Turkey; ${ }^{7}$ Department of Medicine, Aga Khan University Hospital, Karachi 74800, Pakistan; ${ }^{8}$ Department of Clinical Immunology, REA Centre, Tbilisi 0160, Georgia; ${ }^{9}$ Noguchi Memorial Institute for Medical Research, University of Ghana, Legon LG581, Ghana; ${ }^{10}$ Centre of Experimental Medicine "Miguel Layrisse" Venezuelan Research Institute (IVIC), Caracas 21827, Venezuela; ${ }^{11}$ Department of Laboratory Medicine, Seoul National University College of Medicine, Seoul 110-744, Korea; ${ }^{12}$ Centre for Advanced Studies in Functional Genomics, School of Biological Sciences, Madurai Kamaraj University Madurai 625-021, India; ${ }^{13}$ Hung Kuang University, Taichung 433, Taiwan; ${ }^{14}$ Centre for Nephrology and The Anthony Nolan Trust, Royal Free and University College Medical School, London NW3 2QG, United Kingdom; ${ }^{15}$ Department of Infectious and Tropical Diseases, London School of Hygiene and Tropical Medicine, London WC1E 7HT, United Kingdom; ${ }^{16}$ Department of Pathology, Stanford University School of Medicine, Stanford, California 94305, USA; ${ }^{17}$ Moorfields Eye Hospital, London EC1V 2PD, United Kingdom; ${ }^{18}$ Clinical Transplantation Laboratory, Guy's and St. Thomas' Foundation Trust and King's College, London SE1 9RT, United Kingdom; ${ }^{19}$ Stanford Genome Technology Center, Stanford University School of Medicine, Palo Alto, California 94304, USA; ${ }^{20}$ Immune Disease Institute, Boston, Massachusetts 02115, USA

\section{Acknowledgments}

We thank Lewis Lanier for supplying the DX17 and DX31 antibodies.

\section{References}

Alvarez-Arias, D.A. and Campbell, K.S. 2007. Protein kinase C regulates expression and function of inhibitory killer cell Ig-like receptors in NK cells. J. Immunol. 179: 5281-5290.

Artavanis-Tsakonas, K., Eleme, K., McQueen, K.L., Cheng, N.W., Parham, P., Davis, D.M., and Riley, E.M. 2003. Activation of a subset of human NK cells upon contact with Plasmodium falciparum-infected erythrocytes. J. Immunol. 171: 5396-5405.

Bailey, J.A. and Eichler, E.E. 2006. Primate segmental duplications: Crucibles of evolution, diversity and disease. Nat. Rev. Genet. 7: 552-564.

Bashirova, A.A., Martin, M.P., McVicar, D.W., and Carrington, M. 2006. The killer immunoglobulin-like receptor gene cluster: Tuning the genome for defense. Annu. Rev. Genomics Hum. Genet. 7: 277-300.

Belle, I., Hou, L., Chen, M., Steiner, N.K., Ng, J., and Hurley, C.K. 2008. Investigation of killer cell immunoglobulin-like receptor gene diversity in KIR3DL1 and KIR3DS1 in a transplant population. Tissue Antigens 71: 434-439.

Benton, M.J. and Donoghue, P.C. 2007. Paleontological evidence to date the tree of life. Mol. Biol. Evol. 24: 26-53.

Bergstrom, T.F., Erlandsson, R., Engkvist, H., Josefsson, A., Erlich, H.A., and Gyllensten, U. 1999. Phylogenetic history of hominoid DRB loci and alleles inferred from intron sequences. Immunol. Rev. 167: 351-365.

Boyington, J.C., Brooks, A.G., and Sun, P.D. 2001. Structure of killer cell immunoglobulin-like receptors and their recognition of the class I MHC molecules. Immunol. Rev. 181: 66-78.

Braud, V.M., Allan, D.S., O'Callaghan, C.A., Soderstrom, K., D'Andrea, A., Ogg, G.S., Lazetic, S., Young, N.T., Bell, J.I., Phillips, J.H., et al. 1998. HLA-E binds to natural killer cell receptors CD94/NKG2A, B and C. Nature 391: 795-799.

Campbell, M.C. and Tishkoff, S.A. 2008. African genetic diversity: Implications for human demographic history, modern human origins, and complex disease mapping. Annu. Rev. Genomics Hum. Genet. 9: 403-433.

Carr, W.H., Rosen, D.B., Arase, H., Nixon, D.F., Michaelsson, J., and Lanier, L.L. 2007. Cutting Edge: KIR3DS1, a gene implicated in resistance to progression to AIDS, encodes a DAP12-associated receptor expressed on NK cells that triggers NK cell activation. J. Immunol. 178: 647-651.

Cella, M., Longo, A., Ferrara, G.B., Strominger, J.L., and Colonna, M. 1994. NK3-specific natural killer cells are selectively inhibited by Bw4positive HLA alleles with isoleucine 80. J. Exp. Med. 180: 1235-1242.

Chan, H.W., Kurago, Z.B., Stewart, C.A., Wilson, M.J., Martin, M.P., Mace, B.E., Carrington, M., Trowsdale, J., and Lutz, C.T. 2003. DNA methylation maintains allele-specific KIR gene expression in human natural killer cells. J. Exp. Med. 197: 245-255.

Chung, E.K., Yang, Y., Rennebohm, R.M., Lokki, M.L., Higgins, G.C., Jones, K.N., Zhou, B., Blanchong, C.A., and Yu, C.Y. 2002. Genetic sophistication of human complement components C4A and C4B and RP-C4-CYP21-TNX (RCCX) modules in the major histocompatibility complex. Am. J. Hum. Genet. 71: 823-837.

Deeb, S.S. 2006. Genetics of variation in human color vision and the retinal cone mosaic. Curr. Opin. Genet. Dev. 16: 301-307.

Dohring, C., Scheidegger, D., Samaridis, J., Cella, M., and Colonna, M. 1996. A human killer inhibitory receptor specific for HLA-A1,2. J. Immunol. 156: 3098-3101.

Dumas, L., Kim, Y.H., Karimpour-Fard, A., Cox, M., Hopkins, J., Pollack, J.R., and Sikela, J.M. 2007. Gene copy number variation spanning 60 million years of human and primate evolution. Genome Res. 17: 1266-1277.

Feng, J., Garrity, D., Call, M.E., Moffett, H., and Wucherpfennig, K.W. 2005. Convergence on a distinctive assembly mechanism by unrelated families of activating immune receptors. Immunity 22: 427-438.

Foley, B.A., De Santis, D., Van Beelen, E., Lathbury, L.J., Christiansen, F.T., and Witt, C.S. 2008. The reactivity of Bw4+ HLA-B and HLA-A alleles with KIR3DL1: Implications for patient and donor suitability for haploidentical stem cell transplantations. Blood 112: 435-443.

Frazer, K.A., Ballinger, D.G., Cox, D.R., Hinds, D.A., Stuve, L.L., Gibbs, R.A. Belmont, J.W., Boudreau, A., Hardenbol, P., Leal, S.M., et al. 2007. A second generation human haplotype map of over 3.1 million SNPs. Nature 449: 851-861.

Gardiner, C.M., Guethlein, L.A., Shilling, H.G., Pando, M., Carr, W.H., Rajalingam, R., Vilches, C., and Parham, P. 2001. Different NK cell surface phenotypes defined by the DX9 antibody are due to KIR3DL1 gene polymorphism. J. Immunol. 166: 2992-3001.

Gendzekhadze, K., Norman, P.J., Abi-Rached, L., Layrisse, Z., and Parham, P. 2006. High KIR diversity in Amerindians is maintained using few genecontent haplotypes. Immunogenetics 58: 474-480.

Goldstein, D.B. and Chikhi, L. 2002. Human migrations and population structure: What we know and why it matters. Annu. Rev. Genomics Hum. Genet. 3: 129-152.

Gomez-Lozano, N., Estefania, E., Williams, F., Halfpenny, I., Middleton, D., Solis, R., and Vilches, C. 2005. The silent KIR3DP1 gene (CD158c) is transcribed and might encode a secreted receptor in a minority of humans, in whom the KIR3DP1, KIR2DL4 and KIR3DL1/KIR3DS1 genes are duplicated. Eur. J. Immunol. 35: 16-24.

Guethlein, L.A., Older Aguilar, A.M., Abi-Rached, L., and Parham, P. 2007. Evolution of killer cell Ig-like receptor (KIR) genes: Definition of an orangutan KIR haplotype reveals expansion of lineage III KIR associated with the emergence of MHC-C. J. Immunol. 179: 491-504.

Gumperz, J.E., Litwin, V., Phillips, J.H., Lanier, L.L., and Parham, P. 1995. The Bw4 public epitope of HLA-B molecules confers reactivity with natural killer cell clones that express NKB1, a putative HLA receptor. $J$. Exp. Med. 181: 1133-1144.

Hammond, J.A., Guethlein, L.A., Abi-Rached, L., Moesta, A.K., and Parham, P. 2009. Evolution and survival of marine carnivores did not require a diversity of KIR or Ly49 NK cell receptors. J. Immunol. 182: 3618-3627.

Hansasuta, P., Dong, T., Thananchai, H., Weekes, M., Willberg, C., Aldemir, H., Rowland-Jones, S., and Braud, V.M. 2004. Recognition of HLA-A3 and HLA-A11 by KIR3DL2 is peptide-specific. Eur. J. Immunol. 34: 16731679.

Hey, J. 2005. On the number of New World founders: A population genetic portrait of the peopling of the Americas. PLOS Biol. 3: e193. doi: 10.1371/journal.pbio.0030193.

Hiby, S.E., Walker, J.J., O'Shaughnessy, K.M., Redman, C.W., Carrington, M., Trowsdale, J., and Moffett, A. 2004. Combinations of maternal KIR and fetal HLA-C genes influence the risk of preeclampsia and reproductive success. J. Exp. Med. 200: 957-965.

Hollox, E.J., Barber, J.C., Brookes, A.J., and Armour, J.A. 2008. Defensins and the dynamic genome: what we can learn from structural variation at human chromosome band 8p23.1. Genome Res. 18: 1686-1697.

Horton, R., Coggill, P., Miretti, M.M., Sambrook, J.G., Traherne, J.A., Ward, R., Sims, S., Palmer, S., Sehra, H., Harrow, J., et al. 2006. The LRC haplotype project: A resource for killer immunoglobulin-like receptorlinked association studies. Tissue Antigens 68: 450-452.

\section{Genome Research \\ www.genome.org}


Jameson, K.A., Highnote, S.M., and Wasserman, L.M. 2001. Richer color experience in observers with multiple photopigment opsin genes. Psychon. Bull. Rev. 8: 244-261.

Kelley, J., Walter, L., and Trowsdale, J. 2005. Comparative genomics of natural killer cell receptor gene clusters. PLoS Genet. 1: 129-139.

Khakoo, S.I., Rajalingam, R., Shum, B.P., Weidenbach, K., Flodin, L., Muir, D.G., Canavez, F., Cooper, S.L., Valiante, N.M., Lanier, L.L., et al. 2000. Rapid evolution of NK cell receptor systems demonstrated by comparison of chimpanzees and humans. Immunity 12: 687-698.

Khakoo, S.I., Geller, R., Shin, S., Jenkins, J.A., and Parham, P. 2002. The D0 domain of KIR3D acts as a major histocompatibility complex class I binding enhancer. J. Exp. Med. 196: 911-921.

Kimura, M. and Ota, T. 1969. The average number of generations until extinction of an individual mutant gene in a finite population. Genetics 63: 701-709.

Korbel, J.O., Urban, A.E., Affourtit, J.P., Godwin, B., Grubert, F., Simons, J.F., Kim, P.M., Palejev, D., Carriero, N.J., Du, L., et al. 2007. Paired-end mapping reveals extensive structural variation in the human genome. Science 318: 420-426.

Kumar, S., Tamura, K., and Nei, M. 2004. MEGA3: Integrated software for Molecular Evolutionary Genetics Analysis and sequence alignment. Brief. Bioinform. 5: 150-163.

Kummerfeld, S.K. and Teichmann, S.A. 2005. Relative rates of gene fusion and fission in multi-domain proteins. Trends Genet. 21: 25-30.

Lanier, L.L. 2008. Evolutionary struggles between NK cells and viruses. Nat. Rev. Immunol. 8: 259-268.

Marsh, S.G., Parham, P., Dupont, B., Geraghty, D.E., Trowsdale, J., Middleton, D., Vilches, C., Carrington, M., Witt, C., Guethlein, L.A., et al. 2003. Killer-cell immunoglobulin-like receptor (KIR) nomenclature report, 2002. Immunogenetics 55: 220-226.

Martin, M.P., Bashirova, A., Traherne, J., Trowsdale, J., and Carrington, M. 2003. Cutting edge: Expansion of the KIR locus by unequal crossing over. J. Immunol. 171: 2192-2195.

Martin, D.P., Williamson, C., and Posada, D. 2005. RDP2: Recombination detection and analysis from sequence alignments. Bioinformatics 21: 260-262.

Martin, M.P., Qi, Y., Gao, X., Yamada, E., Martin, J.N., Pereyra, F., Colombo, S., Brown, E.E., Shupert, W.L., Phair, J., et al. 2007. Innate partnership of HLA-B and KIR3DL1 subtypes against HIV-1. Nat. Genet. 39: 733-740.

Michaelsson, J., Teixeira de Matos, C., Achour, A., Lanier, L.L., Karre, K., and Soderstrom, K. 2002. A signal peptide derived from hsp60 binds HLA-E and interferes with CD94/NKG2A recognition. J. Exp. Med. 196: 14031414.

Middleton, D., Meenagh, A., and Gourraud, P.A. 2007. KIR haplotype content at the allele level in 77 Northern Irish families. Immunogenetics 59: $145-158$.

Moesta, A.K., Norman, P.J., Yawata, M., Yawata, N., Gleimer, M., and Parham, P. 2008. Synergistic polymorphism at two positions distal to the ligand-binding site makes KIR2DL2 a stronger receptor for HLA-C than KIR2DL3. J. Immunol. 180: 3969-3979.

Moffett, A. and Loke, C. 2006. Immunology of placentation in eutherian mammals. Nat. Rev. Immunol. 6: 584-594.

Moretta, L., Bottino, C., Pende, D., Castriconi, R., Mingari, M.C., and Moretta, A. 2006. Surface NK receptors and their ligands on tumor cells. Semin. Immunol. 18: 151-158.

Nathans, J., Piantanida, T.P., Eddy, R.L., Shows, T.B., and Hogness, D.S. 1986. Molecular genetics of inherited variation in human color vision. Science 232: 203-210.

Norman, P.J., Cook, M.A., Carey, B.S., Carrington, C.V., Verity, D.H., Hameed, K., Ramdath, D.D., Chandanayingyong, D., Leppert, M., Stephens, H.A., et al. 2004. SNP haplotypes and allele frequencies show evidence for disruptive and balancing selection in the human leukocyte receptor complex. Immunogenetics 56: 225-237.

Norman, P.J., Abi-Rached, L., Gendzekhadze, K., Korbel, D., Gleimer, M., Rowley, D., Bruno, D., Carrington, C.V., Chandanayingyong, D., Chang, Y.H., et al. 2007. Unusual selection on the KIR3DL1/S1 natural killer cell receptor in Africans. Nat. Genet. 39: 1092-1099.

O'Connor, G.M., Guinan, K.J., Cunningham, R.T., Middleton, D., Parham, P., and Gardiner, C.M. 2007. Functional polymorphism of the KIR3DL1/ S1 receptor on human NK cells. J. Immunol. 178: 235-241.

Pando, M.J., Gardiner, C.M., Gleimer, M., McQueen, K.L., and Parham, P. 2003. The protein made from a common allele of KIR3DL1 (3DL1*004) is poorly expressed at cell surfaces due to substitution at positions 86 in Ig domain 0 and 182 in Ig domain 1. J. Immunol. 171: 6640-6649.

Parham, P. 2005. MHC class I molecules and KIRs in human history, health and survival. Nat. Rev. Immunol. 5: 201-214.

Pende, D., Biassoni, R., Cantoni, C., Verdiani, S., Falco, M., di Donato, C., Accame, L., Bottino, C., Moretta, A., and Moretta, L. 1996. The natural killer cell receptor specific for HLA-A allotypes: A novel member of the p58/p70 family of inhibitory receptors that is characterized by three immunoglobulin-like domains and is expressed as a $140-\mathrm{kD}$ disulphidelinked dimer. J. Exp. Med. 184: 505-518.

Perry, G.H., Ben-Dor, A., Tsalenko, A., Sampas, N., Rodriguez-Revenga, L., Tran, C.W., Scheffer, A., Steinfeld, I., Tsang, P., Yamada, N.A., et al. 2008. The fine-scale and complex architecture of human copy-number variation. Am. J. Hum. Genet. 82: 685-695.

Posada, D. and Crandall, K.A. 1998. MODELTEST: Testing the model of DNA substitution. Bioinformatics 14: 817-818.

Rajalingam, R., Hong, M., Adams, E.J., Shum, B.P., Guethlein, L.A., and Parham, P. 2001. Short KIR haplotypes in pygmy chimpanzee (Bonobo) resemble the conserved framework of diverse human KIR haplotypes. J. Exp. Med. 193: 135-146.

Rajalingam, R., Parham, P., and Abi-Rached, L. 2004. Domain shuffling has been the main mechanism forming new hominoid killer cell Ig-like receptors. J. Immunol. 172: 356-369.

Redon, R., Ishikawa, S., Fitch, K.R., Feuk, L., Perry, G.H., Andrews, T.D., Fiegler, H., Shapero, M.H., Carson, A.R., Chen, W., et al. 2006. Global variation in copy number in the human genome. Nature 444: 444-454.

Relethford, J.H. 2008. Genetic evidence and the modern human origins debate. Heredity 100: 555-563.

Robinson, J., Waller, M.J., Fail, S.C., and Marsh, S.G. 2006. The IMGT/HLA and IPD databases. Hum. Mutat. 27: 1192-1199.

Ronaghi, M., Karamohamed, S., Pettersson, B., Uhlen, M., and Nyren, P. 1996. Real-time DNA sequencing using detection of pyrophosphate release. Anal. Biochem. 242: 84-89.

Sambrook, J.G., Bashirova, A., Palmer, S., Sims, S., Trowsdale, J., Abi-Rached, L., Parham, P., Carrington, M., and Beck, S. 2005. Single haplotype analysis demonstrates rapid evolution of the killer immunoglobulinlike receptor (KIR) loci in primates. Genome Res. 15: 25-35.

Schneider, S., Roessli, A., and Excoffier, L. 2000. Arlequin ver. 2.0: A software for population genetics data analysis. Genetics and Biometry Laboratory, University of Geneva, Geneva, Switzerland.

Shilling, H.G., Guethlein, L.A., Cheng, N.W., Gardiner, C.M., Rodriguez, R., Tyan, D., and Parham, P. 2002. Allelic polymorphism synergizes with variable gene content to individualize human KIR genotype. J. Immunol. 168: $2307-2315$.

Single, R.M., Martin, M.P., Gao, X., Meyer, D., Yeager, M., Kidd, J.R., Kidd, K.K., and Carrington, M. 2007. Global diversity and evidence for coevolution of KIR and HLA. Nat. Genet. 39: 1114-1119.

Snyder, M.R., Nakajima, T., Leibson, P.J., Weyand, C.M., and Goronzy, J.J. 2004. Stimulatory killer Ig-like receptors modulate T cell activation through DAP12-dependent and DAP12-independent mechanisms. J. Immunol. 173: 3725-3731.

Thananchai, H., Gillespie, G., Martin, M.P., Bashirova, A., Yawata, N., Yawata, M., Easterbrook, P., McVicar, D.W., Maenaka, K., Parham, P., et al. 2007. Cutting Edge: Allele-specific and peptide-dependent interactions between KIR3DL1 and HLA-A and HLA-B. J. Immunol. 178: 33-37.

Thomas, R., Yamada, E., Alter, G., Martin, M.P., Bashirova, A.A., Norman, P.J., Altfeld, M., Parham, P., Anderson, S.K., McVicar, D.W., et al. 2008. Novel KIR3DL1 alleles and their expression levels on NK cells: convergent evolution of KIR3DL1 phenotype variation? J. Immunol. 180: $6743-6750$.

Thompson, J.D., Gibson, T.J., Plewniak, F., Jeanmougin, F., and Higgins, D.G. 1997. The CLUSTAL_X windows interface: Flexible strategies for multiple sequence alignment aided by quality analysis tools. Nucleic Acids Res. 25: 4876-4882.

Trundley, A., Frebel, H., Jones, D., Chang, C., and Trowsdale, J. 2007. Allelic expression patterns of KIR3DS1 and 3DL1 using the Z27 and DX9 antibodies. Eur. J. Immunol. 37: 780-787.

Uhrberg, M., Valiante, N.M., Shum, B.P., Shilling, H.G., Lienert-Weidenbach, K., Corliss, B., Tyan, D., Lanier, L.L., and Parham, P. 1997. Human diversity in killer cell inhibitory receptor genes. Immunity 7: 753-763.

Williams, F., Maxwell, L.D., Halfpenny, I.A., Meenagh, A., Sleator, C., Curran, M.D., and Middleton, D. 2003. Multiple copies of KIR 3DL/S1 and KIR 2DL4 genes identified in a number of individuals. Hum. Immunol. 64: 729-732.

Wilson, M.J., Torkar, M., Haude, A., Milne, S., Jones, T., Sheer, D., Beck, S., and Trowsdale, J. 2000. Plasticity in the organization and sequences of human KIR/ILT gene families. Proc. Natl. Acad. Sci. 97: 4778-4783.

Yang, Z. 2007. PAML 4: Phylogenetic analysis by maximum likelihood. Mol. Biol. Evol. 24: 1586-1591.

Yawata, M., Yawata, N., Draghi, M., Partheniou, F., Little, A.M., and Parham, P. 2008. MHC class I-specific inhibitory receptors and their ligands structure diverse human NK cell repertoires towards a balance of missing-self response. Blood 112: 2369-2380.

Received August 29, 2008; accepted in revised form December 30, 2008. 


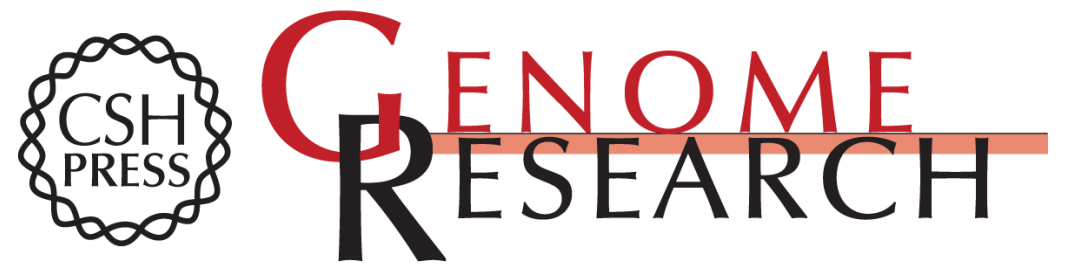

\section{Meiotic recombination generates rich diversity in NK cell receptor genes, alleles, and haplotypes}

Paul J. Norman, Laurent Abi-Rached, Ketevan Gendzekhadze, et al.

Genome Res. 2009 19: 757-769

Access the most recent version at doi:10.1101/gr.085738.108

Supplemental Material

References

License

Email Alerting Service
http://genome.cshlp.org/content/suppl/2009/05/01/19.5.757.DC1

This article cites 78 articles, 33 of which can be accessed free at: http://genome.cshlp.org/content/19/5/757.full.html\#ref-list-1

Receive free email alerts when new articles cite this article - sign up in the box at the top right corner of the article or click here.

\section{Affordable, Accurate Sequencing.}

To subscribe to Genome Research go to: https://genome.cshlp.org/subscriptions 